No.1729

November 2020

\title{
Changing patterns of domestic abuse during Covid-19 lockdown
}

Ria Ivandić

Tom Kirchmaier

Ben Linton 


\begin{abstract}
The effects of preventing a COVID-19 health crisis have had unintended consequences on domestic abuse (DA) victimization. We contribute to the literature on domestic abuse in lockdown by providing insight on how changing patterns of domestic abuse can explain differences in magnitudes reported across studies. We examine the patterns of domestic abuse during the COVID-19 lockdown in Greater London and find that the lockdown changed the nature of reporting and the type of relationship the abuse occurs within. While abuse by current partners as well as family members increased on average by $8.1 \%$ and $17.1 \%$ respectively over the lockdown period, abuse by ex-partners declined by $11.4 \%$. These findings show that reporting the average change in domestic abuse during lockdown can be misleading when designing a policy response. Moreover, we show that all the increase in domestic abuse calls is driven by third party reporting, particularly evident in areas with high density. This suggests that under reporting is present in the lockdown, particularly in households where the abuse cannot be reported by an outsider. Although these findings pertain to the COVID-19 lockdown, they also highlight the role that victim exposure and proximity has in affecting domestic abuse.
\end{abstract}

Key words: crime, Covid-19, lockdown, domestic abuse, domestic violence JEL Codes: J12

This paper was produced as part of the Centre's Community Wellbeing Programme. The Centre for Economic Performance is financed by the Economic and Social Research Council.

\title{
Acknowledgements
}

This research is funded by the Economic and Social Research Council (ESRC) as part of the UK Research and Innovation's rapid response to Covid-19. Kirchmaier and Ivandić gratefully acknowledge this funding under grant number ES/V003917/1. Many thanks to Ben Parnell from the Metropolitan Police Service's Strategic Insight Unit for providing us with the data, and Vaishnavi Agarwal and Neus Torres Blas for outstanding research assistance.

Ria Ivandić and Tom Kirchmaier, Centre for Economic Performance, London School of Economics. Ben Linton, Metropolitan Police Service.

Published by

Centre for Economic Performance

London School of Economics and Political Science

Houghton Street

London WC2A 2AE

All rights reserved. No part of this publication may be reproduced, stored in a retrieval system or transmitted in any form or by any means without the prior permission in writing of the publisher nor be issued to the public or circulated in any form other than that in which it is published.

Requests for permission to reproduce any article or part of the Working Paper should be sent to the editor at the above address.

(c) R. Ivandić, T. Kirchmaier and B. Linton, submitted 2020. 


\section{INTRODUCTION}

There have been numerous news reports that COVID-19 lockdown measures across the globe resulted in a rise in domestic abuse (DA). The New York Times reports that countries worldwide such as France, China, India, Spain and the United Kingdom have witnessed an increase of more than $20 \%$ in domestic violence emergency calls compared to previous months. The effects of preventing a COVID-19 health crisis have had unintended consequences on domestic abuse victimization. Social distancing measures inherently change micro level human interactions, as they force people to spend more time at home. This new setup of greater social proximity between members of a household is likely to have an impact on patterns of domestic abuse. Moreover, the social and financial uncertainty and anxiety could exacerbate existing conflicts between household members.

Recent academic research reports more rigorous estimates of the effects of lockdown on domestic abuse. However, the evidence across these studies is mixed. While some papers report an increase in domestic abuse calls (Leslie and Wilson (2020), Ravindran and Shah (2020)), others report no significant change in domestic abuse over the lockdown (Campedelli, Aziani and Favarin (2020), Payne and Morgan (2020), Piquero et al. (2020)). We contribute to this emerging literature on domestic abuse in lockdown by providing insight on how changing patterns of domestic abuse can explain differences in magnitudes reported across studies. We particularly ask how the lockdown changed the nature of reporting and the type of relationship the abuse occurs within.

This paper assesses the impact of the COVID-19 lockdown on domestic abuse in Greater London. It examines how domestic abuse patterns changed over the lock- 
down period using London Metropolitan Police Service's data on domestic abuse crimes for the period 1st January 2015 to 5th June 2020. This is complemented by calls-for-service data for the period 1st January 2019 to 14th June 2020. Using weekly time series data, we conduct an event studies analysis including a linear time trend and month fixed effects to control for general crime trends and seasonality effects. We complement this analysis by exploiting the census socio-demographic characteristics of the location of the call to check for heterogeneous differences across density and deprivation levels.

Our analysis shows that cumulative numbers failed to show considerable change in abuse levels and masked information about altered patterns of abuse by family, current or ex-partner. Looking at the crime data, we observe a significant shift in composition of abuse during the COVID-19 lockdown. Abuse by current partners and family members is found to have increased by $8.1 \%$ and $17.1 \%$ respectively while ex-partner abuse on the other hand, declined by $11.4 \%$. In sum, this analysis shows that reporting the average change in domestic abuse during lockdown can be very misleading when thinking about a policy response. If ex-partner and current partner abuse have the same share in total abuse, despite diverging trends, the total average might remain stable. Yet in this situation of seemingly no change, victims quarantined with their perpetrators are experiencing significantly higher levels of abuse. This insight can also explain the mixed evidence of the effects of lockdowns on domestic abuse worldwide.

Second, our analysis finds a substantial change in the nature of reporting of domestic abuse. We show that almost all the increase in domestic abuse calls to the police is driven by third party reporting. Testing whether the proximity of neighbours and their ability to overhear and report ongoing domestic abuse incidents is driving the 
increase in reporting, we find that in areas of high density where households live in closer proximity, third party reporting jumps up by $35 \%$ in the aftermath of lockdown, in comparison to around $15 \%$ in areas of low density. These patterns are particularly stark in areas with higher levels of deprivation. This effect can be explained as the lockdown is likely to have trapped many victims with their abuser not giving them the opportunity to report abuse. Yet this does not mean that domestic abuse isn't increasing in households quarantining together, on the contrary, we observe the increase in reporting by neighbours that are now overhearing the abuse. This strongly suggests under reporting driven by the lockdown and present in households where the abuse cannot be reported by an outsider.

Understanding the diverging consequences of the lockdown on victimization can provide evidence for law enforcement agencies to direct interventions to at-risk households and launch information campaigns on the role of community reporting. Although these findings pertain to the specific COVID-19 lockdown, they highlight the role that exposure has in affecting victimization (Bindler, Ketel and Hjalmarsson (2020)) and explaining patterns of domestic abuse.

The paper is divided into five sections. Section 2 discusses existing research on the topic. Section 3 discusses the data and methodology used. Section 4 discusses the results and lastly, Section 5 presents the conclusion and discussion.

\section{LITERATURE REVIEW}

Existing literature documents a strong link between domestic abuse and situations of social and financial stress. Linking socio-economic characteristics of the perpe- 
trator and victim and the number of domestic abuse incidents, Benson et al. (2003) find that economic disadvantage may have a direct influence on intimate partner violence at both the neighbourhood and individual levels. Moreover, Raphael (2000) finds that women in low-income households experienced a higher rate of (reported) violence than those in households with higher incomes. These results suggest that when placed in situations of social and economic tensions, the likelihood of domestic abuse increases. It is expected that, with lockdown introduction, as a significant part of the population became at-risk of job loss, financial concerns became more prevalent in households, amplifying existing tensions and escalating conflict. Research by Bell, Codreanu and Machin (2020) finds that individuals who are young, low-paid, ethnic minorities, and those who have low education levels or live in large families have been disproportionately affected by the current COVID-19 recession. They are more likely to have been furloughed or lose at least half of their working hours compared to those with a degree. This suggests that the groups that were already more vulnerable to domestic abuse are also hardest hit in the economic crisis that will follow, further exacerbating the size of abuse.

The literature identifies two dominant theories on how domestic abuse is incited and perpetuated- Routine activity and crime pattern theories. Routine Activity Theory proposed by Cohen and Felson (1979) suggests that domestic abuse is more likely to occur when there is a convergence of a motivated offender, a suitable target, and the absence of a capable guardian. So, routine activities of the offender and victim define opportunities for the crime. Major disruptions to such activities, say through imposition of lock-downs, would significantly impact routine activity and this would suggest more opportunity for abuse by individuals that the victim is locked down with (e.g. partners and family members) and reduced interaction with those that 
don't live with the victim (e.g. ex-partners). In the case of intimate partner abuse, this would also imply limited ability to seek help from friends and family that could have earlier acted as guardians. As a result, the lockdown is expected to result in an increase in domestic abuse cases in residential locations, something we were also able to establish.

Moreover, there is a body of literature in Criminology that focused on situations and opportunities that trigger crime (Brantingham and Brantingham (1984)). These rely strongly on ordinary interaction in the geographical and social space and therefore are useful in understanding the effect of the social distancing measures. The lockdown loosened the density of social interactions by requiring more people to stay at home. As a result, Campedelli, Aziani and Favarin (2020) hold that crime opportunities are likely to have drastically changed suggesting a contraction in most urban crimes as victim density is reduced. While true for ex-partner abuse, in the case of intimate partner violence the increased spatial proximity due to stay-at-home orders suggests the opposite, hence more instances of abuse are expected.

Findings suggest that more domestic violence occurs in situations when disappointment and emotional tensions are heightened such as an unexpected loss from a home sports team (Card and Dahl (2011)). This is relevant to analyses of crime during lockdown as it is expected that emotional stress would worsen and grow under the pandemic, leading to a high-stress situation comparable to that of a sporting event. In fact, the results are likely to be intensified here because of the extended duration of the high-stress environment.

There is an emerging literature on the changes in crime and domestic abuse caused by the COVID-19 and its responses. The results of these analysis show mixed evidence, with a majority of analysis finding no increases in domestic abuse in lockdown. 
Campedelli, Aziani and Favarin (2020) find that the lockdown policies adopted have not prompted any significant change in intimate partner assault in Los Angeles. Similarly, Payne and Morgan (2020) find that domestic violence in Queensland (Australia) during lockdown was not significantly different from their forecasts for the period given the historical data for the offence using using ARIMA modelling techniques. Another study by Piquero et al. (2020) find no statistically significant increase in domestic violence incidence looking at police data from Dallas (Texas). Using trend analyses and ARIMA forecasting models to estimate domestic violence increases and predict future incidents, they find an immediate increase in domestic abuse in the days after the stay-at-home order however, fail to see any sustained increase or continued higher levels of domestic violence.

A few studies though report positive effects. Research by Leslie and Wilson (2020) documents the impact of the COVID-19 crisis on domestic violence using a differencein-difference approach. They find that the pandemic response measures led to a $10.2 \%$ increase in domestic violence calls. This increase, they find, began before the stay-at-home orders were put in place suggesting that it was not a response to mandated quarantine and therefore might not reverse instantly when measures are lifted. Their data suggests that the increase is not driven by any particular demographic group. Moreover, Ravindran and Shah (2020) use temporal and spatial variation in the intensity of government mandated lockdowns in India to quantify the effect of containment measures on domestic violence. They find that domestic abuse only increased in areas where strict lockdown measures were imposed and they increased by 0.47 standard deviations relative to districts that saw the least strict measures. A study by Perez-Vincent and Carreras (2020) examines the impact of COVID-19 lockdowns on domestic violence in the Argentinean context. The authors find a sig- 
nificant increase of $28 \%$ in calls after mobility restrictions are imposed in Argentina. This study also finds substitution between different reporting mechanisms with a reduction in calls from police and an $82 \%$ increase in direct calls from the victim. A different paper by Gibbons, Murphy and Rossi (2020), also set in Argentina, provides greater insight into the problem. It addresses the concern that the rise in intimate partner violence (IPV) might be driven by an increase in reporting rates. The study compares women whose partners were exempted from complying with the quarantine restrictions to those women whose partners were not. It finds that intimate partner violence and lockdown restrictions are directly proportional with mandated restrictions causing higher levels of partner violence.

Therefore, studies of domestic violence globally in the lockdown reveal mixed results with some showing decreases while others show increase. Our study is unique in two ways. None of these studies split abuse across current and ex-partner abuse and therefore do not provide a detailed account of the nature of the abuse that changes. Another important point to note across all these studies is the imperfect measurement of domestic violence incidents. The changes in domestic violence calls to police could be due to changes in abuse prevalence or in changes of reporting. Social distancing increases the likelihood of third party reporting through neighbours however, decreases probability of self-reporting by the victims. This paper specifically sheds light on the change in the nature of reporting. 


\section{DATA AND METHODOLOGY}

The analysis is based on five years of crime records and two years of calls-for-service data from London's Metropolitan Police Service (MPS). These individual-level observations allow us to provide a reliable empirical assessment of the changes in volumes of domestic abuse during lockdown. Both datasets contain observations up to June 2020. The data for the calls is until 14 June 2020 while that for domestic crimes is until 5 June 2020.

The MPS is the territorial police force responsible for law enforcement in Greater London, which covers a population of around 9 million people (one seventh of the United Kingdom) and currently consists of the 32 London boroughs. Each year, the MPS receives about 2.5 million calls-for-service, out of which 170,000 (7\%) are related to domestic abuse. Of these calls, in 2019 there were about 900,000 crimes, with $9.7 \%$ of them being related to domestic abuse. In the 11 weeks from the beginning of lockdown there were a total of around 45,000 calls to the MPS contact centres related to domestic abuse while during the same time, there were 19,155 domestic abuse offences recorded (42.6\% out of all calls). This means that during the period of the lockdown, domestic abuse became the predominant recorded offence and drove almost half of the demand on policing in Greater London.

For our crime data analysis, we work with two datasets. One dataset available to us is a dataset of all recorded crimes by the MPS over the period of 2.5 years, including all domestic abuse crimes. This is referred to as data on all crimes henceforth in the paper. The second dataset contains records of all domestic abuse crimes over the period of 4.5 years with information on the relationship between the abuser and victim 
included $^{1}$. This is referred to as the relationship data in the rest of our paper. If we match the two datasets, looking only at the overlapping time period from 2018-2020 (2.5 years) and filtering out all non-domestic abuse crimes from the second dataset, we obtain a match of about $76.9 \%$ of all domestic abuse crimes for which we have a recorded relationship.

The data on all crimes contains records from the 1st January 2018 to the 5th June 2020. It contains information about the date and time of the crime recorded, the borough it was recorded in, a unique crime identifier, the offence type and class, the crime major and minor identifiers for domestic abuse crimes, faith based hate crimes and race crimes. In total there are 1,985,304 observations in this data of which approximately $10.6 \%$ of crimes are domestic abuse related.

The relationship data on domestic abuse crimes spans from the 1st January 2015 to the 5th June 2020 and contains information on the relationship between the victim and the offender, the date it was recorded, the crime major, crime minor, offence classification and a unique crime identifier. In total there are 385,873 observations in our dataset. The victim-suspect relationship is classified in the following five categories: Current Partner (36\% of the sample), Ex-Partner (35\%), Other Family/Guardian (21.5\%), Other Non-Family/Guardian (1.5\%) and Unknown (6.1\%). We focus on the first three categories and analyze the differences in their evolution since the beginning of the lockdown in the United Kingdom on the 23rd March 2020. The calls-for-service data has 328,385 observations spanning from 1st January 2019 to 14 th June 2020. This data contains information about date, time and duration of the call, a classification of the reason for the call by police authorities on receiving the call as well as on closing it, location identifiers, level of urgency of the call, the

\footnotetext{
${ }^{1}$ Note that if the crime has no information on the nature of the relationship, it will not be recorded here hence it is a subset of the data on all crimes.
} 
helpline number contacted, its criminal classification identifier (if applicable), the type of caller (victim, witness, third party, etc.) and the associated response time. This data spanned calls-for-service for a number of offences from which the calls relating to domestic abuse were filtered out for this analysis ${ }^{2}$. The data also contains identifiers for calls that were later classified as crimes, a crime reference identifier. In principle, this would allow a perfect match of the domestic crime data into the call data for the same time periods, however, because of measurement error of the crime reference identifer, only a match of about $40 \%$ is achieved and about $27 \%$ when it comes to crimes for which relationship data is present.

The calls-for-service data also contained location identifiers that were converted into an output area format and matched to data from the 2011 United Kingdom census to merge household deprivation levels associated with each location ${ }^{3}$. Output areas (OA) aggregate data for on average only 125 households per OA and are designed by the census as socio-demographically homogeneous areas, hence although the data is not at the individual level, it is very detailed across 25,014 OAs in Greater London. The census for England and Wales classifies households as deprived in four areas: employment, education, health and disability and housing ${ }^{4}$. For every output area in the United Kingdom the census records the number of households that are deprived in one, two, three, four and none of these categories. Using this census data, shares

\footnotetext{
${ }^{2}$ The calls-for-service were also found to include multiple calls for the same incident, i.e. the MPS helplines received calls either by different people or at different times for the same incident. In storing data for such calls, the calls were recorded as "Duplicate" on closing the call. Since we wished to focus on analysing the incidents as opposed to analysing the number of calls received, we dropped these "duplicate" call observations from our calls-for-service data to compute the results reported.

${ }^{3}$ In order to use the relationship information stored in crime data for the call analysis by deprivation levels, the data was also matched to the crime data using the unique identifier. However, since the relationship data is present only for a proportion of the crime data, only $27 \%$ of the data matched and thus the relationship of the victim to the abuser could not be exploited to understand any variations among households of different levels of deprivation.

${ }^{4}$ https://www.statistics.digitalresources.jisc.ac.uk/dataset/classification-household-deprivationgreat-britain-2011
} 
of deprived households in each location were calculated to subsequently compare calls reporting domestic incidents for different deprivation levels ${ }^{5}$. Further, this was matched to all the output areas in Greater London to avoid any selection bias for the locations observed in the call data.

Using the census deprivation indicators, the 25,014 output areas that are part of Greater London and serviced by the MPS were divided into three approximately equal sized categories - least deprived, most deprived, and a middle group ${ }^{6}$. Least deprived areas include $33.43 \%$ of the areas serviced by the MPS, most deprived areas include $32.98 \%$ moderately deprived areas (our middle category of deprivation) includes $33.57 \%$ of the MPS serviced areas. In least deprived areas, on average, there are $53.4 \%$ households with no deprivation and only $0.2 \%$ households deprived in all dimensions. Moderately deprived areas have an average of 39.7\% households of no deprivation and $0.9 \%$ households deprived in all dimensions while most deprived areas have an average of $25.3 \%$ households without deprivation and $1.4 \%$ households deprived in all dimensions. This categorization gives us a mutually exclusive categorization of areas by relative deprivation which allows for a proxy measure of poverty and overall deprivation of the areas serviced.

In addition to deprivation variables, we used the location to merge the density levels associated with each output area reported in the census. This variable gave information on the number of people per hectare in a given output area. This was then used to create above and below median categories based on the levels of density, allowing us to find areas of high and low density amongst those serviced by the MPS. In areas

\footnotetext{
${ }^{5} 369$ observations in the calls data $(0.11 \%)$ did not have any location identifiers and thus could not be used in this part of the analysis.

${ }^{6}$ Each category considers an overall deprivation by aggregating shares of households deprived along any of the dimensions chosen by the census. Greater detail on how these categories were formed is given in the Appendix in section 6.1
} 
of low density, the number of people per hectare, on average, is 57.9 (with a standard deviation of 24.9) while the same for areas of high density is 189.4 (with a standard deviation of 260.7$)^{7}$. Further, on intersecting deprivation levels and density levels we find that $60 \%$ of the most deprived areas are also areas of high density, however the remaining $40 \%$ of most deprived areas had lower levels of density allowing enough variation to study these differences. On the other hand, only $33.8 \%$ of the least deprived areas have a high density.

As we are unable to observe the whole population matched to the victim data, we also study if the lockdown changed the nature of domestic abuse victims and perpetrators using small geographical areas in Greater London. We split the total of around 25,014 output areas in Greater London (serviced by the MPS) in four categories according to the number of calls registered from that area in 2019. Output areas in the bottom quartile had, on average, 4.5 calls per week during 2020. Output areas in the second quartile had 5.65 calls per week on average, while output areas in the third quartile had an average of 8.85 calls per week. Finally, an area in the top quartile had, on average, 18 calls per week associated with it in 2020. This allowed us to study whether high demand areas experienced different changes of domestic abuse trends in the lockdown as compared to lower demand areas.

\footnotetext{
${ }^{7}$ It can be seen from these numbers that the high density category has much greater variation relative to the low density category. However, the high density has a great number of outliers. The maximum density in these areas is 22,600 people but only 23 (out of 25,014 ) areas have a density above 1,500 people.
} 


\subsection{Research Design}

The main results of this research are obtained using an event methodology. We believe that the difference in differences (DiD) research design is not appropriate in this setting. Difference in differences research design looks at the differential effect of a treatment by comparing the average change over time in the outcome variable for the treatment group, compared to the average change over time for the control group. However, as the COVID-19 pandemic possibly affected every single crime category and every locality, there is no appropriate control group. Even before the lockdown was imposed or mobility levels dropped in a given city or country, constant news about the health and economic consequences of the pandemic would have affected uncertainty and anxiety levels across different cities, associated with DA, biasing the pre-lockdown trends in the control group.

In the event study methodology, the COVID-19 lockdown is treated as an event assuming that in absence of this event the time series data would have continued on the same trend as until the event occurred. This involves comparing outcomes within a unit before and after "treatment" (in this case, the lockdown). As long as there are no systemic changes over time, aside from the mandated lockdown, the difference between the two states can be viewed as causal. This would take care of any bias on characteristics that does not change with time. Further, we also include a linear time trend and month fixed effects in our model to control for general crime trends and seasonality effects that might otherwise bias our results. We extend the analysis then by including the leads and lags following the first week of the lockdown. 
In Equation 1 we capture the effect of the lockdown as:

$$
\operatorname{Ln} Y_{t, m}=\beta \operatorname{Lockdown}_{t, m}+\delta_{m}+\theta t+u_{t, m}
$$

where $y_{t, m}$ is the dependent variable log transformed as $\operatorname{Ln} Y_{t, m}$ of the analysis at time $t$ in month $m$; Lockdown $n_{t}$ is a dummy variable equal to one during the period $t$ of lockdown, $\delta_{m}$ is a dummy for every month, and $t$ captures the linear time trend. In Equation 2 the specifying equation is written to include time dynamics:

$$
\operatorname{Ln} Y_{t, m}=\sum_{t=-3}^{3} \beta_{3, t}\left[\text { Event }_{t, m}\right]+\delta_{m}+\theta t++u_{t, m}
$$

where $y_{t, m}$ is the dependent variable log transformed as $L n y_{t, m}$ of the analysis at time $t$ in month $m$; Event $t_{t}$ is a dummy variable equal to one when $t$ is equal to the first week of lockdown, $\delta_{m}$ is a dummy for every month, and $t$ captures the linear time trend.

A part of our analysis describing changes in trends as compared to pre-lockdown levels features visualised descriptive analysis. To do so we computed the 'baseline' level, i.e. the "before lockdown" domestic abuse calls-for-service, by using the average weekly calls for the period 6 January 2020 to 2 March 2020. This period was chosen because it could capture existing trends of domestic abuse calls in 2020. Although the lockdown was imposed on 23 March 2020, a number of people had started voluntarily staying at home before the government mandated orders came into effect. As a result the baseline average was calculated using data only until 2 March 2020. This baseline acts as the counter factual for our analysis. 


\section{RESULTS}

In Figure 1, we visualise the overall trends in domestic abuse during lockdown as compared to trends in 2019 and the weeks preceding the lockdown in 2020.

Figure 1: Weekly calls for domestic incidents/crimes, 2019 vs. 2020

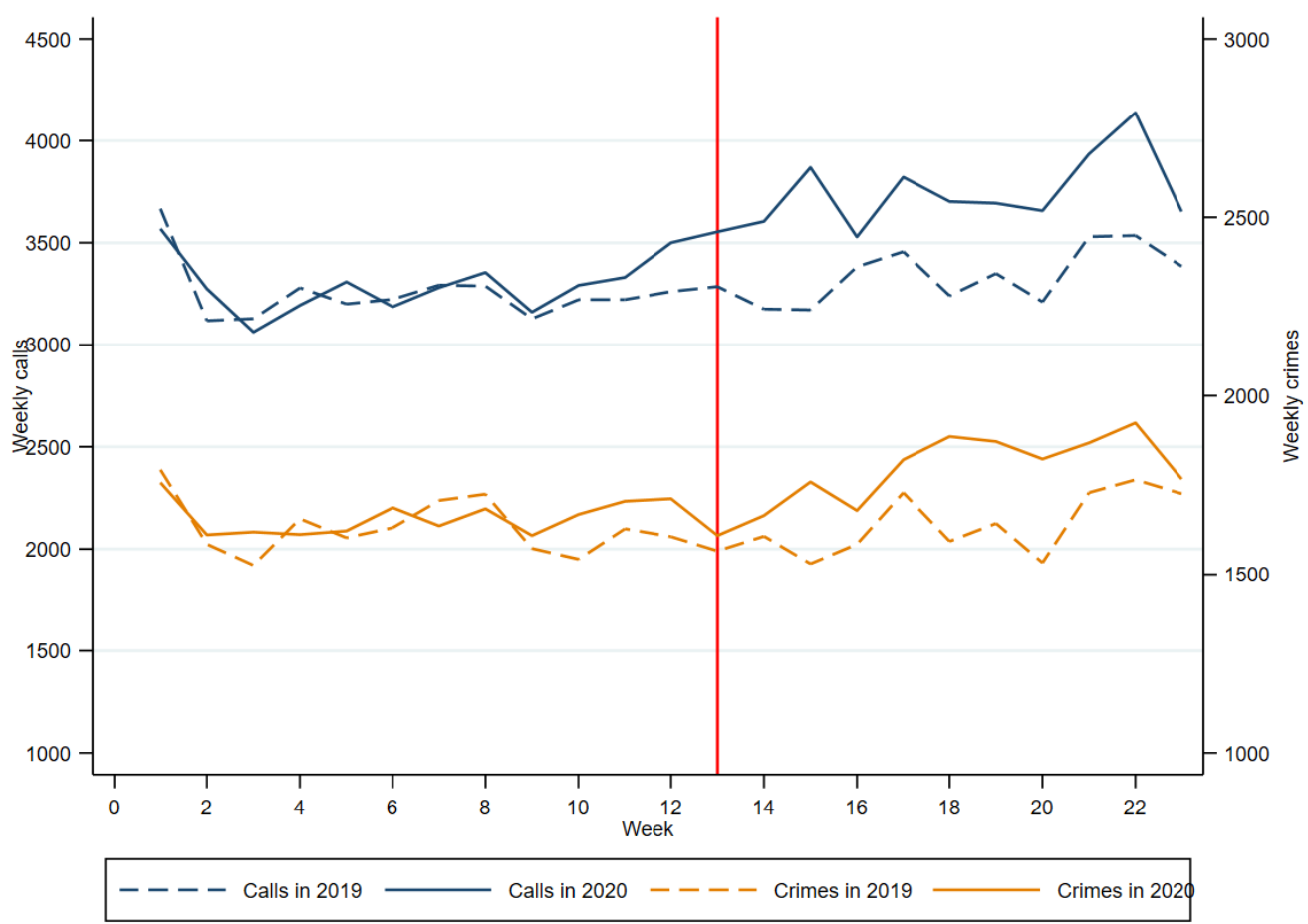

Note: The blue lines represent to domestic abuse related calls-for-service. They correspond to the "Weekly calls" axis on the left. The orange lines represent all domestic abuse related crimes in that period. They correspond to the "Weekly crimes" axis on the right. Data containing all crimes has been used to compute the weekly crimes shown in the figure.

The first observation is that from the first week of January until the beginning of March, the weekly trends in calls and crimes in 2020 exactly mirrored the trends in 2019. Two weeks before the lockdown, in the first week of March, we observe 
that the 2020 and 2019 trends start diverging and the number of calls starts increasing and remains higher all throughout lockdown. We also observe in Figure 1 that domestic abuse crimes during lockdown also increased relative to trends from the previous year, yet at a lower and more volatile rate. We further explore these changes in more detail and rigour in the following section and discuss mechanisms behind the changing nature of domestic abuse in lockdown.

We also observe that the 2020 numbers started deviating from the 2019 trend two weeks before the lockdown was imposed in the United Kingdom. Even before the lockdown, the news from Italy started spreading in March leading to higher levels of anxiety and controlling behaviour (associated with domestic abuse) that might have preceded the significant drops in mobility levels. This is also indicative that the difference in differences research design exploiting variation across cities or countries may not be appropriate in this setting.

\subsection{Domestic Abuse Crimes}

In Figure 1, we showed that domestic abuse crimes experienced higher levels during the lockdown period than the same period last year. Yet, the nature of domestic abuse crime varies significantly as for example current partner abuse makes up an equal share as ex-partner abuse (35-36\% each). The lockdown induced changes including a significant drop in mobility, reduced drinking alcohol in pubs or sporting events, yet increased the time spent at home and levels of financial and social anxiety. These changes could have affected the nature of abuse drastically. 
Disaggregating domestic abuse crimes by the relationship characteristics between the victim and offender reveals an important change in the nature of domestic abuse when interpreting overall trends in domestic abuse. In A.1 we visualise the weekly trends in domestic crimes by relationship type of the abuser to the victim. Two things become clear - after the lockdown (displayed as the red line) there is a drastic change in trends as ex-partner domestic crimes drop while current partner and within family domestic crimes increase. Second, we observe that the sudden increase in current and family domestic abuse mirrors the peak in the last week of the year when the holidays lead to households spending time predominantly at home with each other.

Table 1: Weekly Domestic Abuse Crimes by Relationship: Event Study Regression Output

\begin{tabular}{lcccc}
\hline VARIABLES & $(1)$ & $(2)$ & $(3)$ & $(4)$ \\
& All Relationships & Current Partners & Ex Partners & Family/Guardian \\
\hline After lockdown & 0.016 & $0.085^{* * *}$ & $-0.094^{* * *}$ & $0.164^{* * *}$ \\
& $(0.014)$ & $(0.020)$ & $(0.022)$ & $(0.021)$ \\
Observations & & & & \\
R-squared & 0.654 & 282 & 282 & 282 \\
Month FE & YES & 0.259 & 0.530 & 0.594 \\
Linear trend & YES & YES & YES & YES \\
\hline
\end{tabular}

Note: Robust standard errors in parentheses. ${ }^{* * *} \mathrm{p}<0.01,{ }^{* *} \mathrm{p}<0.05,{ }^{*} \mathrm{p}<0.1$. The entries are coefficient estimates from event study regressions where the dependent variable is log transformed. The After lockdown variable is a dummy variable identifying the domestic abuse crimes committed after the lockdown imposition in our sample. For all the regressions whose coefficients are reported here, monthly fixed effects and a linear trend were used to control for seasonal trends and general crime trends. This uses data from 01 Jan 2015 to 05 June 2020 which reports domestic abuse crimes and the relationship between the abuser and victim. All dependent variables are in logs.

To formalise these results, we use the event methodology described in the previous section, controlling for month fixed effects and a linear time trend. In Table 1 
we show the results from the model in Equation 1. During the lockdown, on average, we find that the current partner abuse crimes increased by about $8.5 \%$ over the lockdown period, domestic abuse by family members rose by about $16.4 \%$. However, ex-partner crimes decreased by about $9.4 \%$. While the overall level of domestic abuse crimes having any recorded relationship data remained unchanged during lockdown, the overall level of domestic abuse crimes increased by around $4.5 \%$ as shown in the first column of Table A. $2^{8}$.

To examine the individual week time dynamics, we estimate Equation 2 and show the results in Table A.3. We visualise the weekly coefficients from these regressions in Figure 2 with the confidence intervals of the coefficients additionally displayed in Figures A.2 and A.3. In addition to these diverging trends, the time variations masked by them is also of interest. Figure 2 shows that crimes between ex-partners dropped immediately at the start of the lockdown while crimes between current partners gradually increased as weeks in lockdown passed. Domestic abuse crimes peaked five weeks after the lockdown, driven primarily by increase in current partner abuse and abuse by family members, while ex-partner abuse was consistently lower. Within-family abuse sharply increased one week before the lockdown and remained around 20\% higher even 10 weeks after the lockdown was imposed.

In sum, this analysis shows that reporting the average change in domestic abuse during lockdown can be very misleading when thinking about a policy response. If expartner and current partner abuse have the same share in total abuse, despite diverging trends, the total average might remain stable. Yet in this situation of seemingly no change, victims quarantined with their perpetrators are experiencing significantly

\footnotetext{
${ }^{8}$ Even in this smaller sample of 2.5 years, the coefficients on the types of relationship remain unchanged.
} 
higher levels of abuse. This insight can also explain the mixed evidence of the effects of lockdowns on domestic abuse worldwide.

Figure 2: Crimes by type of relationship

(a) Current Partners

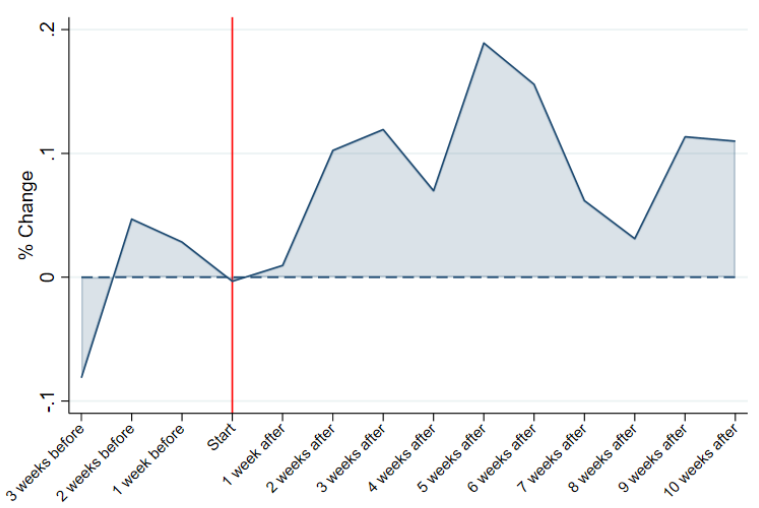

Red line signifies the start of the lockdown on March 23rd

(c) Family/Guardian

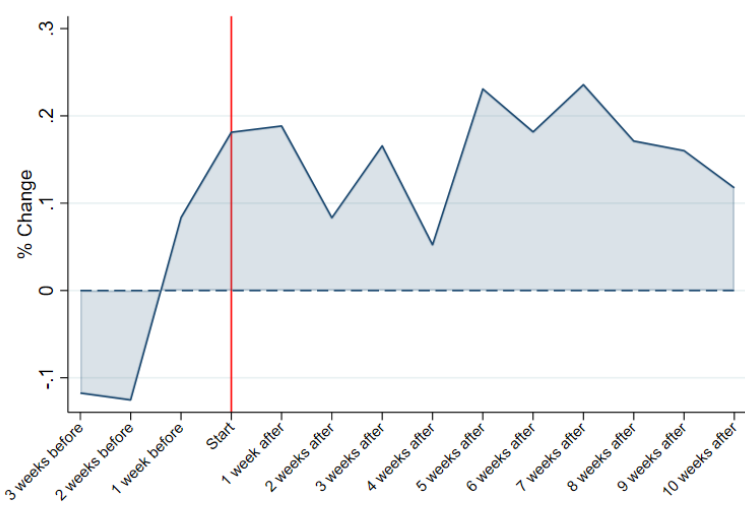

Red line signifies the start of the lockdown on March 23rd

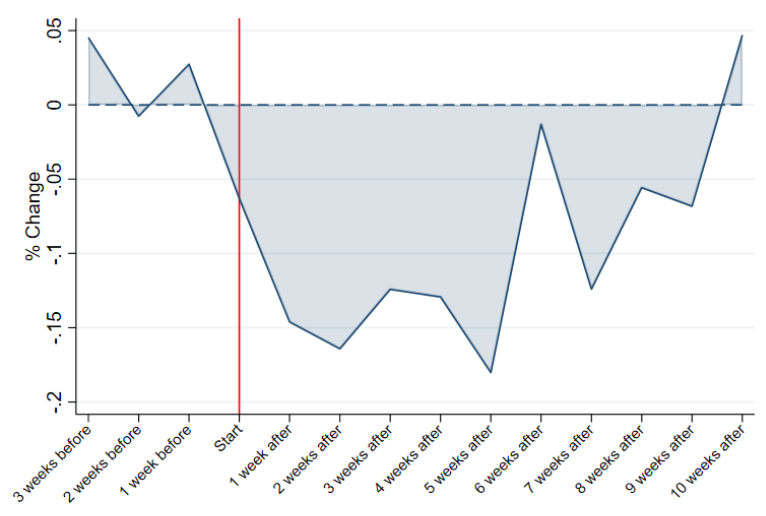

Red line signifies the start of the lockdown on March 23rd (b) Ex Partners

(d) All Relationships

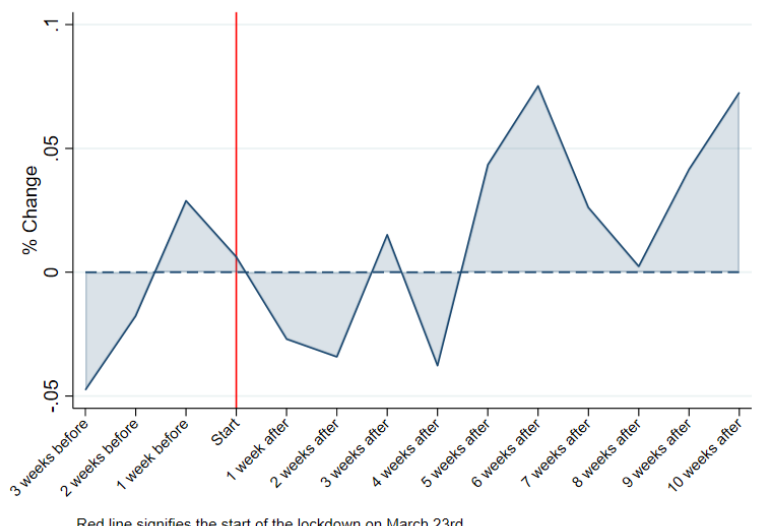

Note: The figure plots the coefficients for weekly log-transformed domestic abuse crimes by relationship type compared to the start of lockdown as \% change. The red line signifies the start of the lockdown on 23rd March 2020. 


\subsection{Domestic Abuse Calls-For-Service}

Figure 1 shows that the weekly numbers of domestic abuse calls-for-service in January and February this year closely follow the numbers observed in 2019. From the week of 16 to 22 March 2020, we see that the divergence from 2019 numbers starts as domestic abuse calls increase by 400 calls, on average, weekly as compared to the same week last year. While this divergence begins a week before the lockdown started, this was the week that a large number of workers were advised to work from home and uncertainty about the scale of the pandemic and its economic implications spread over news. Since the beginning of March, this has led to an excess of 2,200 domestic abuse calls in total, as compared to the same time last year. Further, in Figure A.4, we see that average domestic abuse calls increased by around 15\% every week as compared to baseline with a weekly increase to around $20-25 \%$ above baseline in the three weeks from 5 to 26 April.

Using the past 16 months of data, we break down weekly trends in violent and non-violent calls in Figure A.5. Both violent and non-violent domestic abuse calls increase during the weeks since March 16th as compared to the same period last year. While the relative increases were the same magnitude, in absolute terms non-violent calls increased by about 340 per week on average relative to their 2019 levels while violent calls increase by an average of 60 per week after the lockdown started.

Our data also provides information about the caller providing insight into changes in reporting behaviour as a result of quarantine. We present the calls by victim and third party callers for 2020 and 2019 in Figure 3. An important insight becomes ev- 
Figure 3: Weekly calls for domestic incidents/crimes by caller type

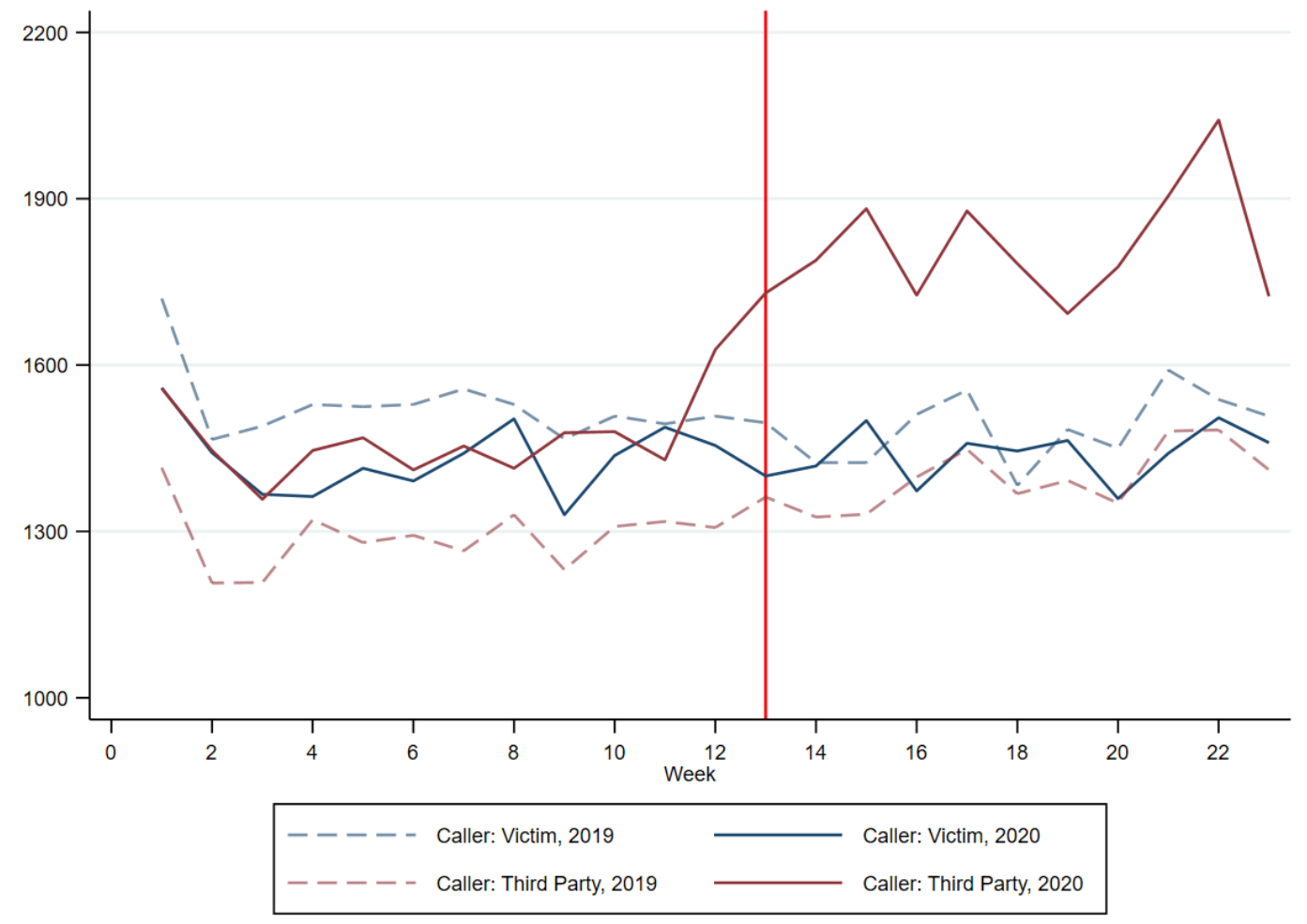

ident - the whole discussed increase in domestic abuse calls is driven by third party reporting of domestic abuse incidents in lockdown. Third party reporting increases by an average of 416 calls per week relative to 2019 levels after lockdown started, or on average around $30 \%$. On the other hand, we see no increase in reporting by victims. This can be understood in the context of quarantine given the consistent supervision and proximity to the abuser and the reduced chances of reporting for victims. Yet at the same time, neighbours and individuals living in proximity to the victim were forced to remain at home and thus, had greater opportunity to report any incidents. 
Figure 4: Calls for service for domestic incidents/crimes by caller type and density level

(a) Areas of low density

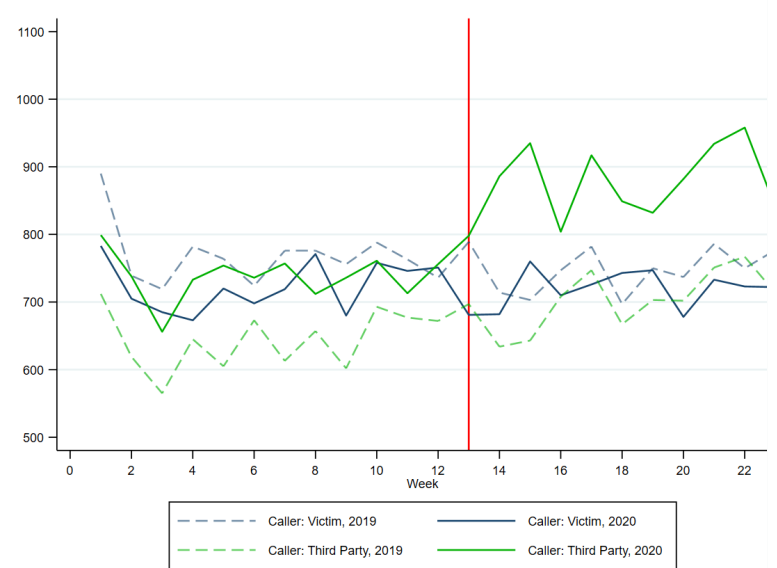

(b) Areas of high density

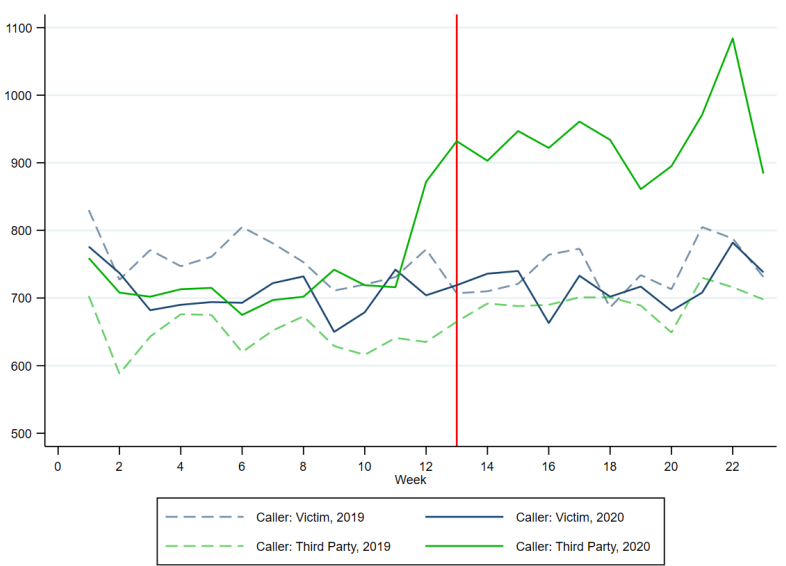

Note: The red line indicates the start of the lockdown on 23rd March, 2020.

To specifically test this mechanism whether the proximity of neighbours and their ability to overhear and report ongoing domestic abuse incidents is driving the increase in reporting, we conduct the same analysis on calls in areas of low versus high density, defined in the Data section. If the hypothesis were true, we would expect third party reporting to be exacerbated in high density areas. This is exactly what we find in Figure 4. In areas of high density where households live in closer proximity lockdown third party reporting jumps up by $35 \%$ in the aftermath of lockdown, in comparison to around $15 \%$ in areas of low density.

Furthermore, we examine two further mechanisms of change in domestic abuse during lockdown - does the magnitude of increase differ in areas where historically demand was high or low, or is the magnitude of increase different in areas that are most or least deprived. To assess whether the change differed in areas with different historical demand for domestic abuse, in Figure A. 6 we plot the observed increase relative 
to baseline in domestic abuse calls across four quartiles (areas of differing demand for service) in the weeks of the lockdown. A large increase is seen in all four quartiles with the least rise is the areas with the highest existing demand (Panel A.6d). We also use the calls-for-service data matched to UK census data from 2011 in order to analyze the calls relating to domestic abuse by the level of deprivation of the associated area $^{9}$.

Figure A.7 shows the weekly calls for domestic abuse incidents and its evolution after the lockdown was imposed in 2020 for areas of high and low deprivation. To best understand the pattern and avoid mistaking any seasonal trends as the effect of the lockdown, we also plot the weekly calls for 2019. In absolute terms most of the increase occurs in areas with most deprived households. In order to examine this in relative terms, we plot the weekly calls for domestic abuse incidents as a percentage of the average number of calls received in our chosen baseline period ( 6 January 2020 to 2 March 2020) for each associated deprivation category in Figure A.8. We see substantive increases from baseline average level for all areas of deprivation which peak nine weeks after the lockdown was imposed. The change in DA calls in the most deprived areas is around 4pp. $(21 \%)$ higher on average (at around $18.5 \%$ ) than the change in the least deprived areas (at around $14.5 \%)^{10}$.

Since the lockdown meant neighbours and more family members being at home as

\footnotetext{
${ }^{9}$ These results are robust to different definitions of deprivation. They are also robust to social grade as defined by the 2011 census for England and Wales as a system of demographic classification based on occupation. The grades were grouped, as is standard to compute shares of middle and working class households. Based on this, we created groups of areas as predominantly middle or working class and found the results exactly as predicted by the deprivation level analysis.

${ }^{10}$ To further understand the different patterns of domestic abuse related calls-for-service across categories of deprivation, we check if daily trends for calls differ between the areas. Figure A.14 plots the average daily increase in calls by day of week for the weeks of the lockdown in 2020 relative to that in 2019 for each area deprivation category (The zero value in the figure represents the number of calls in 2019 on that day for the associated deprivation category). For least deprived areas we see that on average the increase in calls, relative to 2019, occurs most on Thursday while for the most deprived areas the number of calls are higher on Thursday and Friday.
} 
opposed to at work, it also meant more people could overhear an ongoing incident and report it. To check this we also plotted the calls by the caller type for each category of area deprivation in Figure A.10. Each panel in the figure shows calls by the victim as well as those by third party individuals for 2020 and 2019. For all categories, we see a sharp rise in third party reporting two weeks before start of lockdown. This rise seems to become greater as areas become more deprived. In areas of low deprivation we see a rise of 59.8 calls, on average, by third party callers in 2020 relative to 2019 for the weeks after lockdown started. Alternatively, for areas of high deprivation, we see an average increase of 123.4 calls by third party callers relative to 2019 after the lockdown was imposed. Further, what is also striking is that in addition to third party callers we see a decrease in reporting by the victim.

Given such large increases in third party reporting for areas of high deprivation, we also verified the reporting behaviour for areas of low and high density within the most deprived areas. Looking specifically at calls from areas of maximum deprivation, we see in Figure 5 that the most deprived areas of higher density witness a significantly higher rise in third party callers. Amongst the high deprivation areas, areas of low density saw an average increase in 66 calls by third party callers per week, relative to 2019 levels, after the lockdown while high density areas saw an increase of 122 calls by third party callers on average per week after lockdown. 
Figure 5: Calls for service for domestic incidents/crimes by caller type and density level in most deprived areas

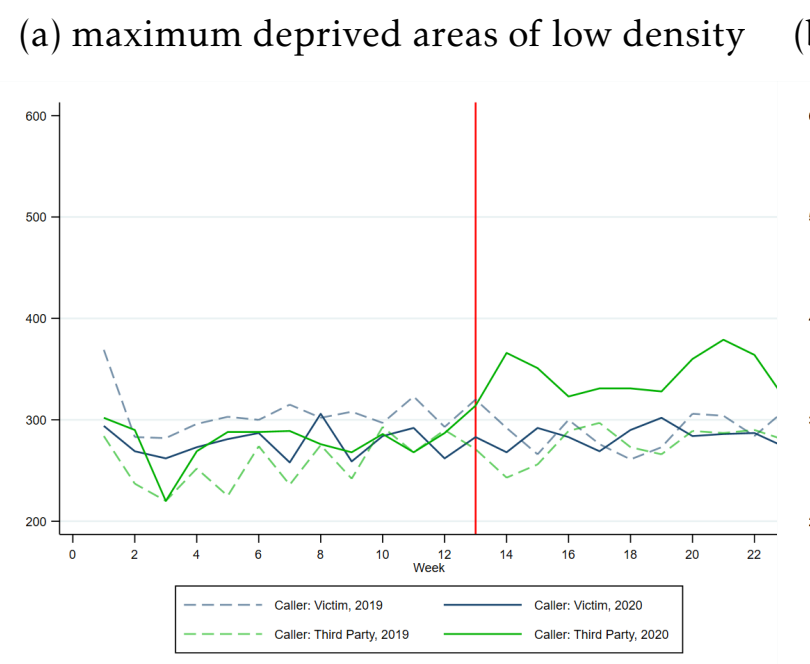

(b) maximum deprived areas of high density

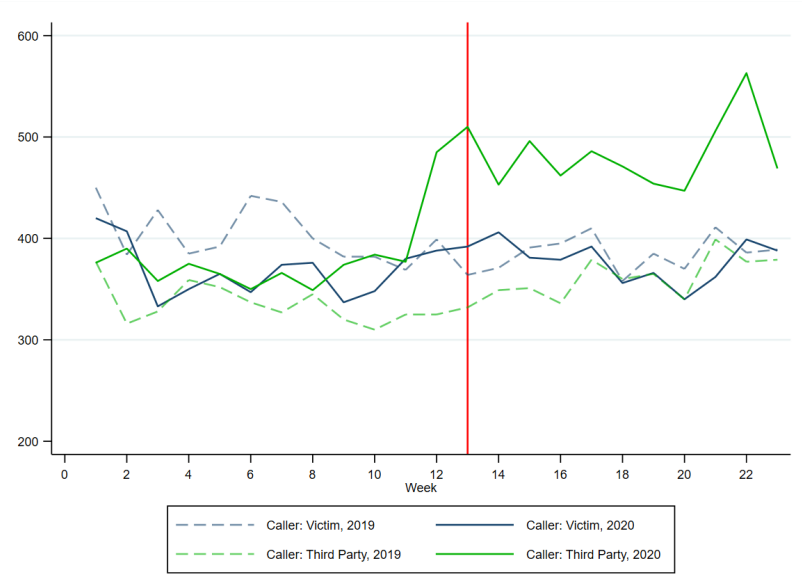

Note: The red line indicates the start of the lockdown on 23rd March 2020.

This effect can be explained as the lockdown is likely to have trapped many victims with their abuser in close quarters. Under constant supervision by the abuser under the lockdown, it is unlikely that victims will find opportunities to report abuse. This is what we see in the data. Yet this does not mean that domestic abuse isn't increasing in households quarantining together, on the contrary, we observe the increase in reporting by neighbours that are now overhearing the abuse. This strongly suggests a level of under reporting driven by the lockdown and present in households where the abuse cannot be reported by an outsider. 


\section{DISCUSSION AND CONCLUSION}

Public health approaches focusing on slowing down the COVID-19 spread in the form of stay-at-home orders had considerably wider societal costs. One such cost, backed by inconclusive empirical evidence, has been the effect of the lockdown on domestic abuse.

This paper is based on a complete and detailed administrative dataset from London's Metropolitan Police Service, but differs from the existing literature in that it relies on a dataset that uniquely integrates calls to the police, crime records, and precise geolocation of each call record. The latter allows us to relate the information on calls to socio-economic information of the caller for very small geographical areas. This integration allows us to draw conclusions that complement the existing literature by providing a more refined understanding of how and where the lockdown has affected domestic abuse and reporting patterns.

We make a number of important contributions. First, we highlight the importance of viewing domestic abuse levels in terms of its components as opposed to as a whole. We show that average increase in abuse levels masked significant information about altered patterns, with abuse by current partners and family members increasing by $8.1 \%$ and $17.1 \%$ respectively, while ex-partner abuse declined by $11.4 \%$. The existing literature does not differentiate between the changes in the different types of victimization, yet this has important implications both for policing strategy and potential long term counselling needs. Second, by exploiting socio-demographic characteristics and density levels of small geographic areas, we find a substantial change in the nature of reporting of domestic abuse. We find that in areas of high density where households live in closer proximity, third party reporting jumps up by $35 \%$ in the 
aftermath of lockdown, in comparison to around 15\% in areas of low density. These patterns are particularly stark in areas with higher levels of deprivation. This effect can be explained as the lockdown is likely to have trapped many victims with their abuser not giving them the opportunity to report abuse.

Going forward, police services will need to develop effective intervention strategies, and learn how to direct scarce policing resources for if and when lockdown conditions return in the future. More importantly, these findings have general applicability also in times outside COVID-19 lockdowns, namely that they speak more broadly on the explanation that presence and proximity of perpetrators to victims plays a significant role in explaining patterns of domestic abuse. Crime rates are a function of the extent to which potential victims and offenders interact. Policing strategies and legal mechanisms can be developed to allow for an efficient separation - both ex-ante and ex-post - of high risk victims from their perpetrators in environments when emotions or uncertainty are affected. 


\section{REFERENCES}

Bell, B., M. Codreanu and S. Machin. 2020. "What can previous recessions tell us about the Covid-19 downturn?" A CEP Covid-19 analysis, Paper No.007 .

Benson, Michael L., Greer L. Fox, Alfred DeMaris and Judy Van Wyk. 2003. "Neighborhood disadvantage, individual economic distress and violence against women in intimate relationships." Journal of Quantitative Criminology, 19(3):207-235.

Bindler, Anna, Nadine Ketel and Randi Hjalmarsson. 2020. "Costs of Victimization." Handbook of Labor, Human Resources and Population Economics pp. 1-31.

Brantingham, P. and P. Brantingham. 1984. "Patterns in Crime." New York: Macmillan ; London : Collier Macmillan. Print .

Campedelli, Gian Maria, Alberto Aziani and Serena Favarin. 2020. "Exploring the effect of 2019-nCoV containment policies on crime: The case of los angeles." arXiv preprint arXiv:2003.11021.

Card, David and Gordon B. Dahl. 2011. "Family violence and football: The effect of unexpected emotional cues on violent behavior." Q J Econ, 126(1):103-143, 2011. 21853617 [pmid] .

Cohen, Lawrence E. and Marcus Felson. 1979. "Social change and crime rate trends: A routine activity approach." American Sociological Review, 44(4):588-608 .

Gibbons, M. Amelia, Tommy E. Murphy and Martin A. Rossi. 2020. "Confinement and Intimate Partner Violence: The Short-Term Effect of COVID-19." Chapter 2, Inter-American Development Bank Technical Note No IDB-TN-1956 .

Leslie, Emily and Riley Wilson. 2020. "Sheltering in place and domestic violence: Evidence from calls for service during COVID-19." Available at SSRN 3600646.

Payne, Jason Leslie and Anthony Morgan. 2020. "COVID-19 and Violent Crime: A comparison of recorded offence rates and dynamic forecasts (ARIMA) for March 2020 in Queensland, Australia." SocArXiv g4kh7, Center for Open Science .

Perez-Vincent, Santiago M. and Enrique Carreras. 2020. "Evidence from a Domestic Violence Hotline in Argentina." Chapter 1, Inter-American Development Bank Technical Note $N^{o}$ IDB-TN-1956 .

Piquero, A. R., J. R. Riddell, S. A. Bishopp, C. Narvey, J. A. Reid and N. L. Piquero. 2020. "Staying Home, Staying Safe? A Short-Term Analysis of COVID-19 on Dallas Domestic Violence." American Journal of Criminal Justice, 1-35. Advance online publication. https://doi.org/10.1007/s12103-020-09531-7 . 
Raphael, J. 2000. "Saving Bernice: Battered Women, Welfare, and Poverty." Northeastern series on gender, crime, and law, Northeastern University Press .

Ravindran, Saravana and Manisha Shah. 2020. "Unintended Consequences of Lockdowns: COVID-19 and the Shadow Pandemic." NBER Working Paper No. 27562, JEL No. I15,I18,J12,J16,O15 . 


\section{APPENDIX}

\subsection{Method used for Deprivation Categorization:}

The census for England and Wales classifies households as deprived in four areas: employment, education, health and disability and housing. For every output area in the United Kingdom the census records the number of households that are deprived in one, two, three, four and none of these dimensions (instead of by individual dimension of deprivation). This is used by us to derive shares for the number of houses deprived (by number of deprivation dimensions) in each output area (OA). Then, for every OA, these shares were marked as high or low for each individual group. If an area had a share of houses higher than $23 \%$ in a given group (eg. deprived in all four dimensions) we marked that as a high share while a number lower than $3.5 \%$ was marked as a low share ${ }^{11}$.

Next, to ensure a mutually exclusive categorization, we marked OAs as most or least deprived only if the shares were similar across groups. OAs which had high shares in more than one group were categorized as most deprived and those having low shares in more than one group were called least deprived. To further strengthen our categories, all OAs which had a share of no deprived households above $99 \%$ were marked least deprived areas and those having less than 5\% households with no deprivation were marked most deprived. As a result, the 25,014 output areas that are part of Greater London and serviced by the MPS were divided into three approximately equal sized categories- least deprived, most deprived, and a middle group. Least deprived areas have at most $7 \%$ deprived households and include $33.43 \%$ of the areas serviced by the MPS. Most deprived areas have at least $46 \%$ deprived households and include $32.98 \%$ of the MPS serviced areas and the moderately deprived areas (our middle category of deprivation)consists of all areas which don't fall into the previous two categories and includes $33.57 \%$ of the MPS serviced areas. This provides us with a mutually exclusive categorization of areas by relative deprivation which allows for a proxy measure of poverty and overall deprivation of the areas serviced.

In our category of the least deprived areas, the average share of houses without any deprivation in a given output area is $53.4 \%$ and only $0.2 \%$ households in any

\footnotetext{
${ }^{11}$ These numbers were chosen after careful study of the distribution to ensure that the resultant groups would be approximately equal in size. It was found that most of the Greater London areas serviced by the MPS do not contain very high shares (of say above $60 \%$ ) of deprived households. Therefore, we kept our thresholds on the lower side.
} 
area within this category are deprived in all four dimensions. In areas of the moderate deprivation, the average share of households without any deprivation is $39.7 \%$ and those deprived in all dimensions is $0.9 \%$. There is sufficient variation within this category and it can be read as areas where households from different levels of deprivation and wealth mix. Alternatively, in our categorization of most deprived areas the average share of houses with no deprivation is $25.3 \%$ and that of houses deprived in all four dimensions are $1.4 \%$. On average, $34.7 \%$ households are deprived along one dimension, $28.5 \%$ along two dimensions and $9.9 \%$ along three dimensions of deprivations in these areas of high deprivation. 
Table A.1: Summary Statistics: Weekly Crimes

\begin{tabular}{lccccc}
\hline \hline & $(\mathrm{N})$ & $($ Mean$)$ & $(\mathrm{SD})$ & $($ Min) & $($ Max $)$ \\
\hline \hline Domestic Abuse Crimes & 126 & $1,646.833$ & 130.357 & 1,331 & 1,984
\end{tabular}

\begin{tabular}{lccccc} 
By relationship type: & \multicolumn{7}{l}{} \\
\hline All & 282 & $1,365.904$ & 120.632 & 1,099 & 1,753 \\
Current Partner & 282 & 491.028 & 41.215 & 403 & 652 \\
Ex-Partner & 282 & 477.046 & 41.285 & 358 & 623 \\
Family/Guardian & 282 & 83.819 & 32.531 & 16 & 155 \\
Other Non-Family & 282 & 20.213 & 6.495 & 2 & 38 \\
Unknown relationship & 282 & 293.798 & 38.176 & 218 & 421
\end{tabular}

Note: The unit of observation is a week. The relationship data on domestic abuse related crimes spans 1 st January 2015 to 5 th June 2020 . The overall crime data received without any relationship variables, and including other crimes, spans 1st January 2018 to 5th June 2020. For the overlapping time periods $76.91 \%$ of the total domestic abuse crime data matches to the relationship data. 
Table A.2: Weekly Domestic Abuse Crimes: Event Study Regression Output

\begin{tabular}{lcccc}
\hline & $(1)$ & $(2)$ & $(3)$ & $(4)$ \\
VARIABLES & All Crimes & Current Partners & Ex Partners & Family/Guardian \\
\hline \multirow{2}{*}{ After lockdown } & $0.045^{\star *}$ & $-0.077^{* * *}$ & $0.073^{* * *}$ & $0.141^{* * *}$ \\
& $(0.019)$ & $(0.028)$ & $(0.027)$ & $(0.028)$ \\
Observations & 126 & 126 & 126 & 126 \\
R-squared & 0.562 & 0.428 & 0.381 & 0.581 \\
Month FE & YES & YES & YES & YES \\
Linear trend & YES & YES & YES & YES \\
\hline
\end{tabular}

Note: Robust standard errors in parentheses. ${ }^{* * *} \mathrm{p}<0.01,{ }^{* *} \mathrm{p}<0.05,{ }^{*} \mathrm{p}<0.1$. The entries are coefficient estimates from event study regressions. The After lockdown variable is a dummy variable identifying the domestic abuse crimes committed after the lockdown imposition in our sample. For all the regressions whose coefficients are reported here, monthly fixed effects and a linear trend were used to control for seasonal trends and general crime trends. This uses data from 01 Jan 2018 to 05 June 2020 for all domestic abuse crimes recorded in the period. 
Figure A.1: Weekly Domestic Crimes By Relationship Type (01 Jan 2019 to 05 June 2020)

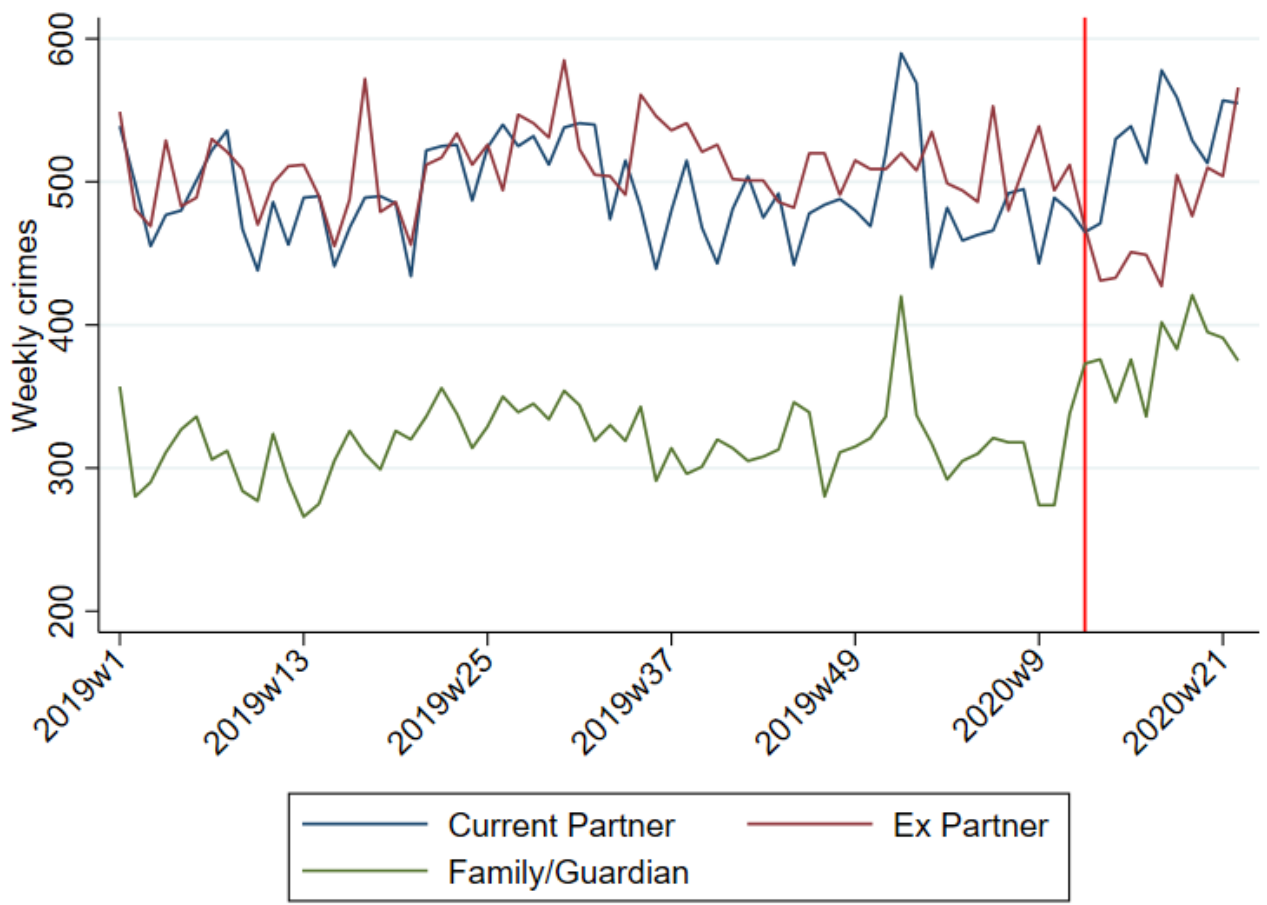

Note: The red line indicates the start of lockdown on 23rd March 2020. The figure is computed using the crime data where there is relationship data. 
Figure A.2: Confidence Intervals of Time Series Regression

(a) Weekly Current Partner DA

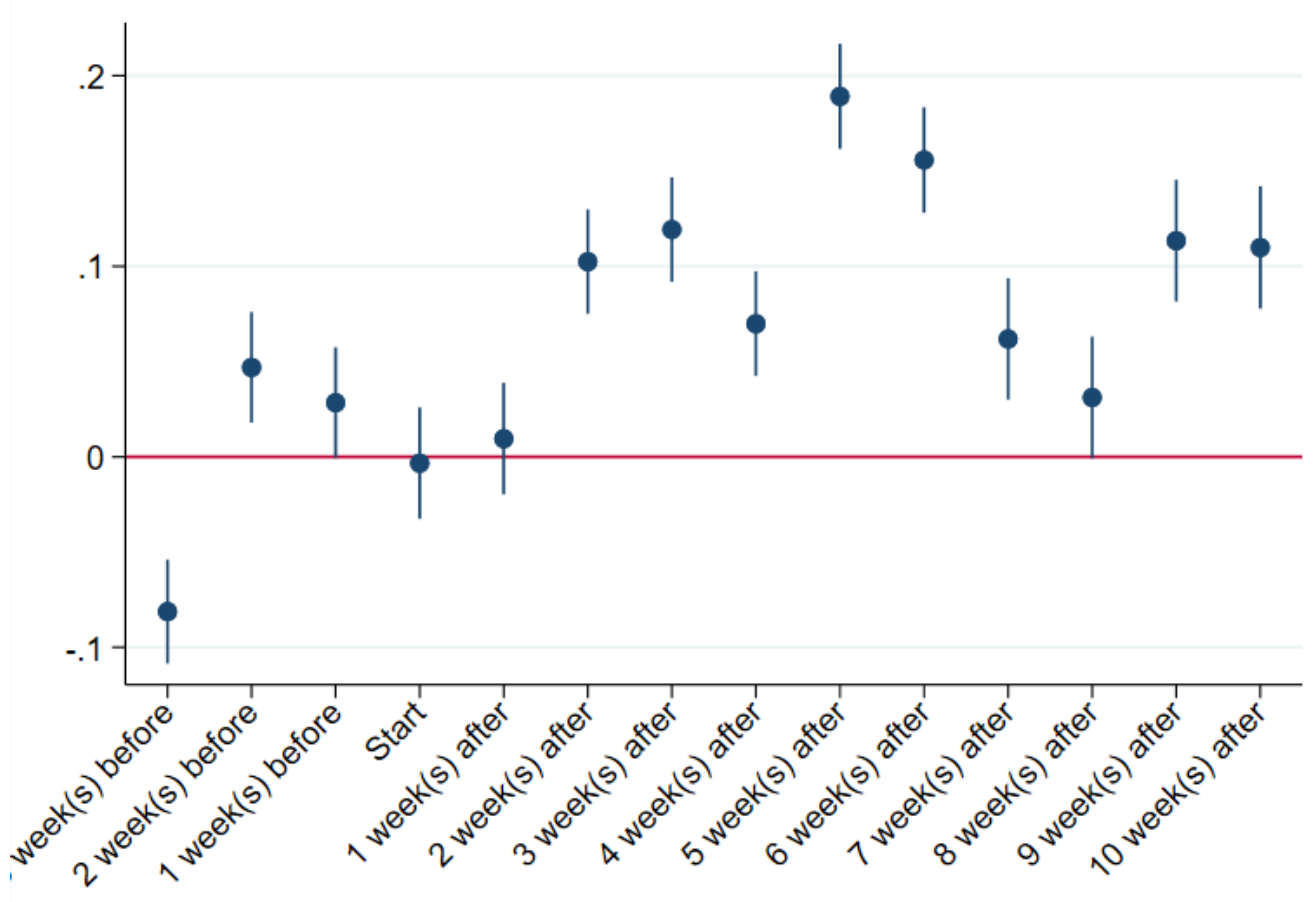

(b) Weekly Ex Partner DA

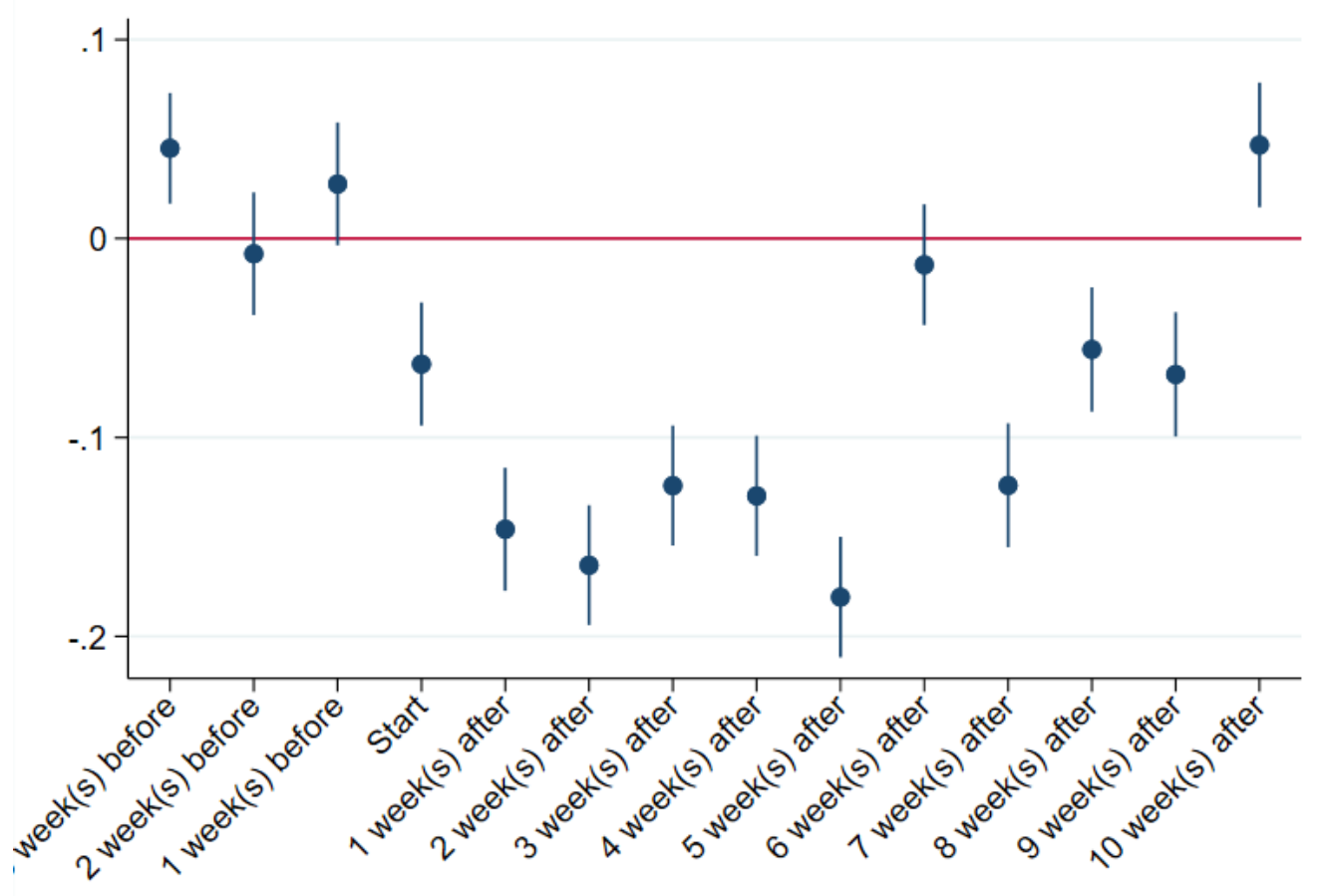


Figure A.3: Confidence Intervals of Time Series Regression

(a) Weekly Family DA

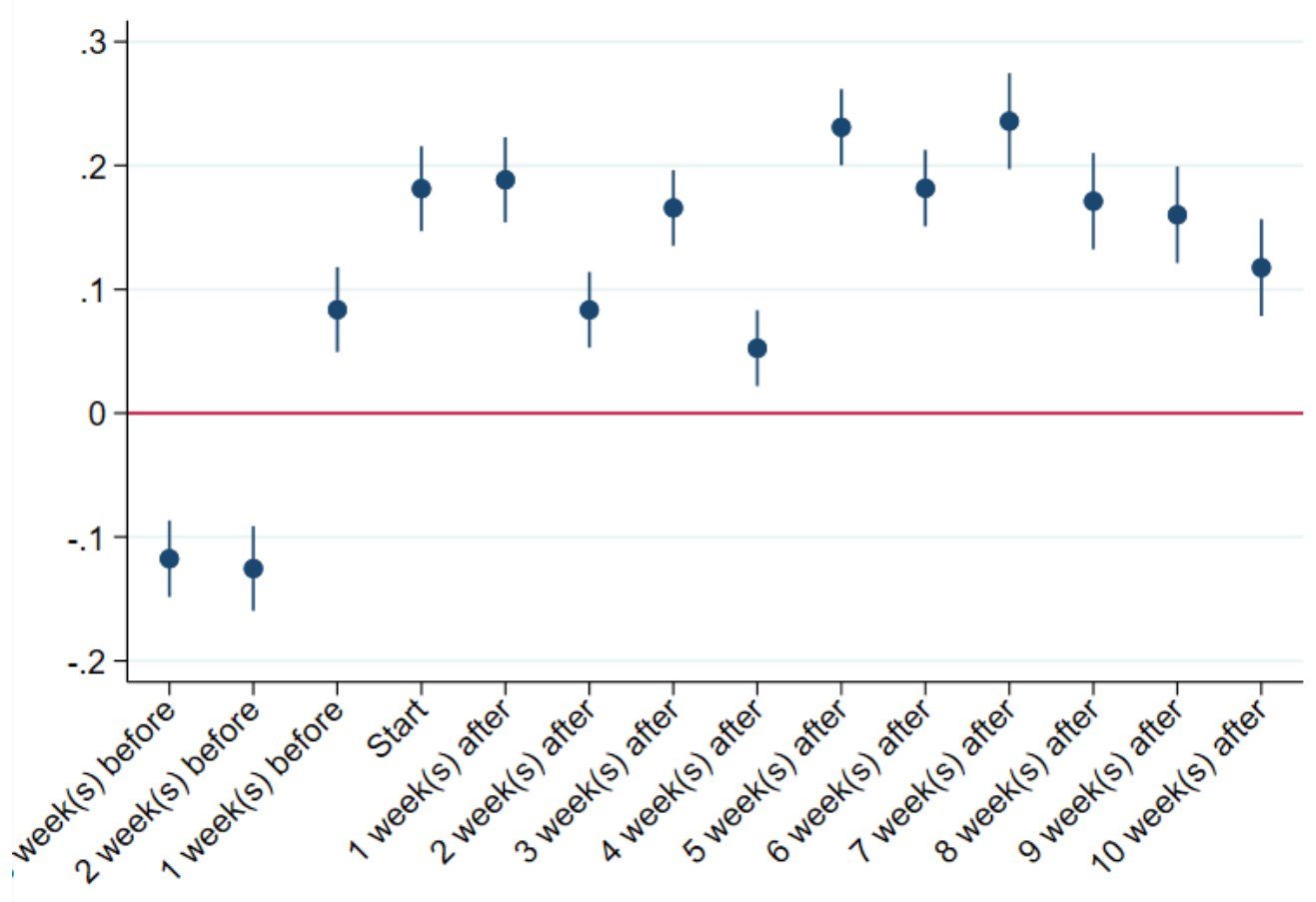

(b) All DA

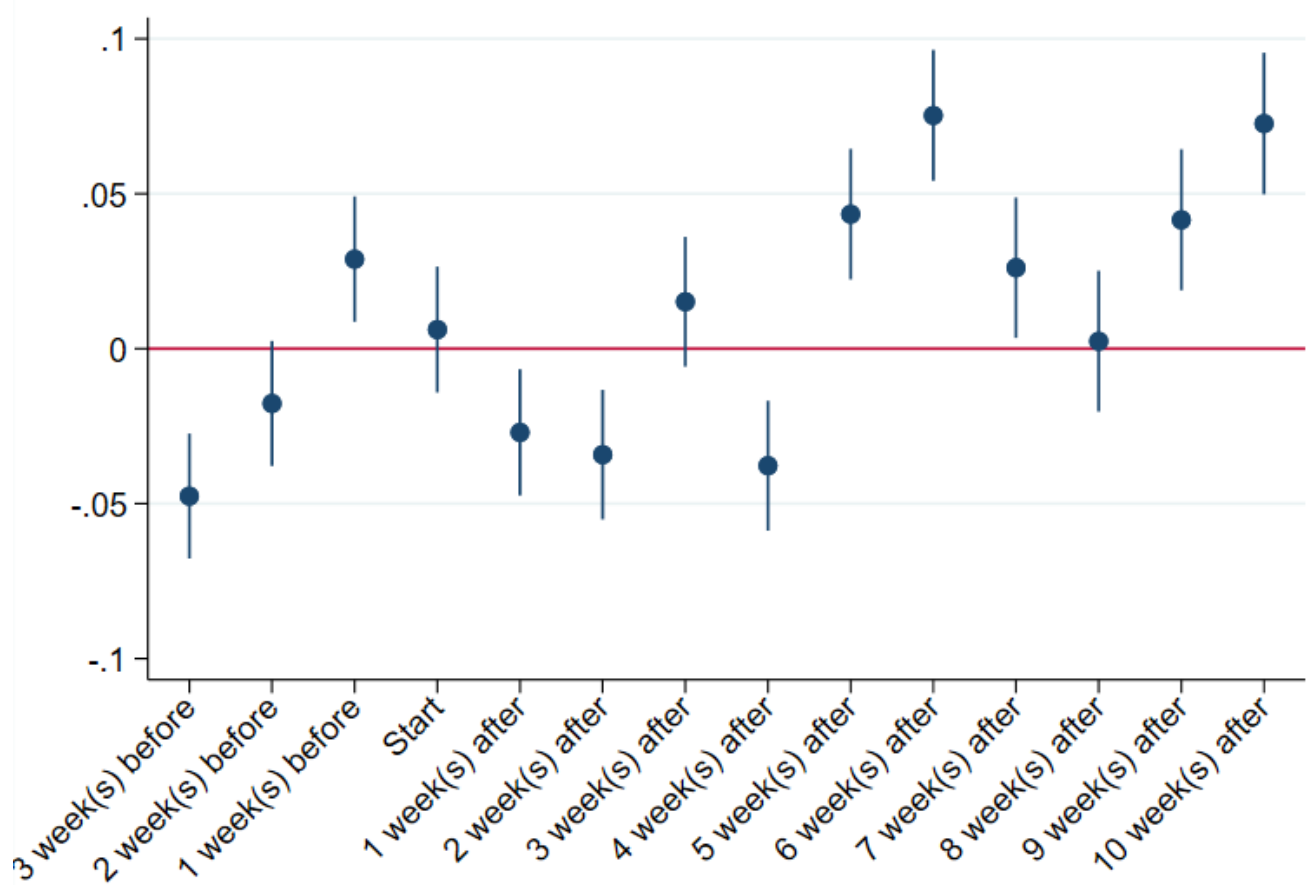

The graph plots regression coefficients for the event studies regression of weekly domestic abuse crimes by relationship type. The variables are logarithmic and so the dots plot the coefficients indicating a \% change in weekly crimes by relationship type. The blue line shows a 95\% confidence interval. Crime data which has relationship data recorded for it was used for this analysis. 
Table A.3: Weekly Domestic Abuse Crimes: Event Study Regression Output

\begin{tabular}{|c|c|c|c|c|}
\hline VARIABLES & $\begin{array}{c}(1) \\
\text { All relationships }\end{array}$ & $\begin{array}{c}(2) \\
\text { Current Partners } \\
\end{array}$ & $\begin{array}{c}(3) \\
\text { Ex Partners } \\
\end{array}$ & $\begin{array}{c}\text { (4) } \\
\text { Family/Guardian } \\
\end{array}$ \\
\hline 3 week(s) before & $\begin{array}{c}-0.048^{* * *} \\
(0.010)\end{array}$ & $\begin{array}{c}-0.081^{* * *} \\
(0.014)\end{array}$ & $\begin{array}{l}0.045^{* * *} \\
(0.014)\end{array}$ & $\begin{array}{c}-0.118^{* * *} \\
(0.016)\end{array}$ \\
\hline 2 week(s) before & $\begin{array}{l}-0.018^{\star} \\
(0.010)\end{array}$ & $\begin{array}{c}0.047^{\star * *} \\
(0.015)\end{array}$ & $\begin{array}{l}-0.008 \\
(0.016)\end{array}$ & $\begin{array}{c}-0.125^{\star * *} \\
(0.017)\end{array}$ \\
\hline 1 week(s) before & $\begin{array}{l}0.029^{* * *} \\
(0.010)\end{array}$ & $\begin{array}{l}0.028^{*} \\
(0.015)\end{array}$ & $\begin{array}{l}0.027^{\star} \\
(0.016)\end{array}$ & $\begin{array}{l}0.084^{* * *} \\
(0.017)\end{array}$ \\
\hline Start & $\begin{array}{c}0.006 \\
(0.010)\end{array}$ & $\begin{array}{l}-0.003 \\
(0.015)\end{array}$ & $\begin{array}{c}-0.063^{* * *} \\
(0.016)\end{array}$ & $\begin{array}{l}0.181^{* * *} \\
(0.017)\end{array}$ \\
\hline 1 week(s) after & $\begin{array}{c}-0.027^{* * *} \\
(0.010)\end{array}$ & $\begin{array}{c}0.010 \\
(0.015)\end{array}$ & $\begin{array}{c}-0.146^{* * *} \\
(0.016)\end{array}$ & $\begin{array}{l}0.189^{* * *} \\
(0.017)\end{array}$ \\
\hline 2 week(s) after & $\begin{array}{c}-0.034^{* * *} \\
(0.011)\end{array}$ & $\begin{array}{c}0.102^{* * *} \\
(0.014)\end{array}$ & $\begin{array}{l}-0.164^{* * *} \\
(0.015)\end{array}$ & $\begin{array}{l}0.083^{* * *} \\
(0.015)\end{array}$ \\
\hline 3 week(s) after & $\begin{array}{c}0.015 \\
(0.011)\end{array}$ & $\begin{array}{l}0.119^{* * *} \\
(0.014)\end{array}$ & $\begin{array}{c}-0.124^{* * *} \\
(0.015)\end{array}$ & $\begin{array}{l}0.166^{* * *} \\
(0.016)\end{array}$ \\
\hline 4 week(s) after & $\begin{array}{c}-0.038^{* * *} \\
(0.011)\end{array}$ & $\begin{array}{c}0.070^{* * *} \\
(0.014)\end{array}$ & $\begin{array}{l}-0.129^{* * *} \\
(0.015)\end{array}$ & $\begin{array}{l}0.052^{* * *} \\
(0.016)\end{array}$ \\
\hline 5 week(s) after & $\begin{array}{c}0.043^{* * *} \\
(0.011)\end{array}$ & $\begin{array}{l}0.189^{* * *} \\
(0.014)\end{array}$ & $\begin{array}{l}-0.180^{* * *} \\
(0.015)\end{array}$ & $\begin{array}{l}0.231^{* * *} \\
(0.016)\end{array}$ \\
\hline 6 week(s) after & $\begin{array}{c}0.075^{* * *} \\
(0.011)\end{array}$ & $\begin{array}{c}0.156^{* * *} \\
(0.014)\end{array}$ & $\begin{array}{l}-0.013 \\
(0.015)\end{array}$ & $\begin{array}{l}0.182^{* * *} \\
(0.016)\end{array}$ \\
\hline 7 week(s) after & $\begin{array}{l}0.026^{* *} \\
(0.012)\end{array}$ & $\begin{array}{c}0.062^{* * *} \\
(0.016)\end{array}$ & $\begin{array}{c}-0.124^{* * *} \\
(0.016)\end{array}$ & $\begin{array}{c}0.236^{* * *} \\
(0.020)\end{array}$ \\
\hline 8 week(s) after & $\begin{array}{c}0.002 \\
(0.012)\end{array}$ & $\begin{array}{l}0.031^{*} \\
(0.016)\end{array}$ & $\begin{array}{c}-0.056^{* * *} \\
(0.016)\end{array}$ & $\begin{array}{c}0.171^{* * *} \\
(0.020)\end{array}$ \\
\hline 9 week(s) after & $\begin{array}{l}0.042^{* * *} \\
(0.012)\end{array}$ & $\begin{array}{l}0.113^{* * *} \\
(0.016)\end{array}$ & $\begin{array}{l}-0.068^{* * *} \\
(0.016)\end{array}$ & $\begin{array}{l}0.160^{* * *} \\
(0.020)\end{array}$ \\
\hline 10 week(s) after & $\begin{array}{l}0.073^{* * *} \\
(0.012)\end{array}$ & $\begin{array}{l}0.110^{* * *} \\
(0.016)\end{array}$ & $\begin{array}{c}0.047^{* * *} \\
(0.016)\end{array}$ & $\begin{array}{l}0.118^{* * *} \\
(0.020)\end{array}$ \\
\hline Linear trend & $\begin{array}{c}0.001^{* * *} \\
(0)\end{array}$ & $\begin{array}{l}-0 \\
(0)\end{array}$ & $\begin{array}{c}0.001^{\star * *} \\
(0)\end{array}$ & $\begin{array}{c}0.001^{* * *} \\
(0)\end{array}$ \\
\hline Observations & 282 & 282 & 282 & 282 \\
\hline R-squared & 0.663 & 0.282 & 0.553 & 0.609 \\
\hline Month FE & YES & YES & YES & YES \\
\hline Linear trend & YES & YES & YES & YES \\
\hline
\end{tabular}

Note: Robust standard errors in parentheses. ${ }^{* *} 3 \$<0.01,{ }^{* *} \mathrm{p}<0.05,{ }^{*} \mathrm{p}<0.1$. The table reports the coefficients from event studies regressions of weekly crimes by relationship type on dummy variables for week. The data used is crime data by relationship and covers the period 01 Jan 2015 to 05 June 2020. 
Table A.4: Summary Statistics: Weekly Calls-for-service

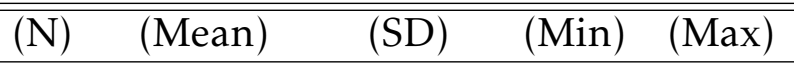

All areas:

$\begin{array}{lccccc}\text { Domestic Abuse Calls } & 76 & 3,420.829 & 257.235 & 2,570 & 4,138 \\ \text { Calls by Victim } & 76 & 1,478.079 & 99.134 & 958 & 1,732 \\ \text { Calls by Third Party } & 76 & 1,495.461 & 177.903 & 1,207 & 2,042\end{array}$

Areas of least deprivation:

$\begin{array}{llllll}\text { Domestic Abuse Calls } & 76 & 660.461 & 56.089 & 467 & 790 \\ \text { Calls by Victim } & 76 & 283.961 & 24.048 & 179 & 341 \\ \text { Calls by Third Party } & 76 & 286.632 & 35.930 & 218 & 381\end{array}$

Areas of moderate deprivation:

$\begin{array}{lccccc}\text { Domestic Abuse Calls } & 76 & 1,210.303 & 94.085 & 937 & 1,507 \\ \text { Calls by Victim } & 76 & 515.697 & 39.591 & 321 & 583 \\ \text { Calls by Third Party } & 76 & 529.921 & 66.300 & 418 & 750\end{array}$

Areas of most deprivation:

$\begin{array}{lccccc}\text { Domestic Abuse Calls } & 76 & 1,550.066 & 122.476 & 1,166 & 1,913 \\ \text { Calls by Victim } & 76 & 678.421 & 50.289 & 458 & 829 \\ \text { Calls by Third Party } & 76 & 678.908 & 83.725 & 548 & 927\end{array}$

Areas of low density:

$\begin{array}{lccccc}\text { Domestic Abuse Calls } & 76 & 1,716.816 & 131.113 & 1,263 & 2,127 \\ \text { Calls by Victim } & 76 & 743.053 & 53.654 & 475 & 890 \\ \text { Calls by Third Party } & 76 & 744.829 & 86.988 & 565 & 975\end{array}$

Areas of high density:

\begin{tabular}{lccccc}
\hline Domestic Abuse Calls & 76 & $1,704.013$ & 138.187 & 1,307 & 2,183 \\
Calls by Victim & 76 & 735.026 & 52.431 & 483 & 849 \\
Calls by Third Party & 76 & 750.632 & 97.914 & 588 & 1,084
\end{tabular}


Figure A.4: Weekly calls for domestic incidents/crimes as \% of baseline

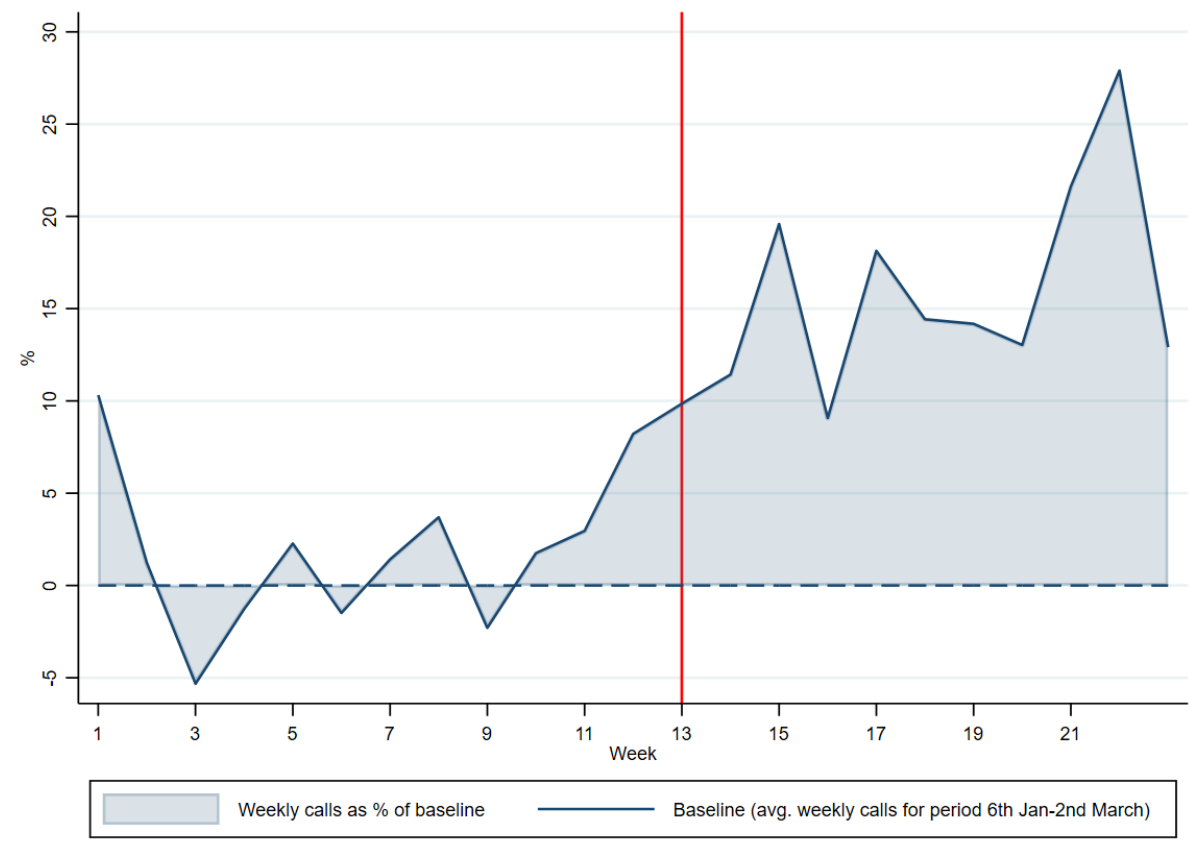

Note: The red line indicates the start of the lockdown on March 23rd, 2020. The dotted line indicates the baseline average associated with the deprivation category. The solid line shows the weekly calls as a percentage of baseline calls. The chosen baseline period is 6th January 2020 to 2nd March 2020. 
Figure A.5: Weekly calls for domestic incidents/crimes - Violence

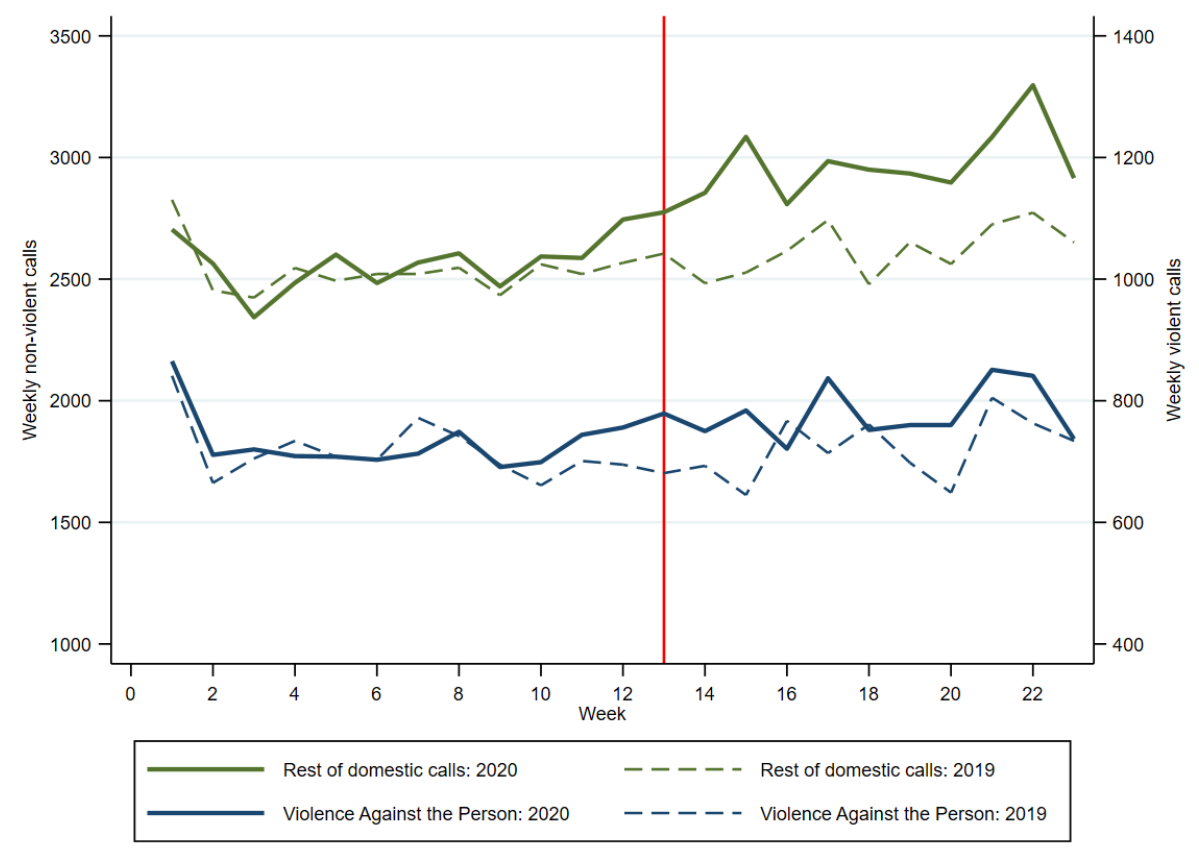

The green lines represent calls reporting non-violent abuse and correspond to the "Weekly non-violent calls" axis on the left. The blue lines represent calls reporting violent abuse and correspond to the "Weekly violent calls" axis on the right. The calls were segregated based on the description noted in the data on closing the call. The red line indicates the start of the lockdown on 23rd March, 2020. 
Figure A.6: Demand for service by \% of baseline in Output Areas in London

(a) lowest quartile of demand

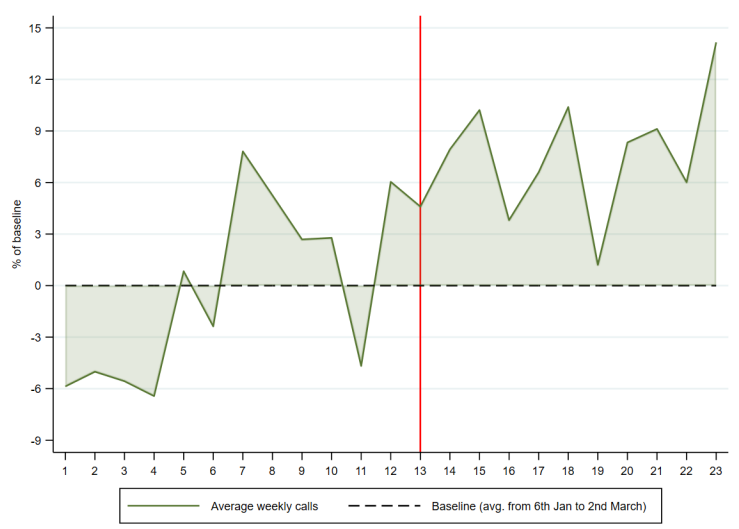

(c) third quartile of demand

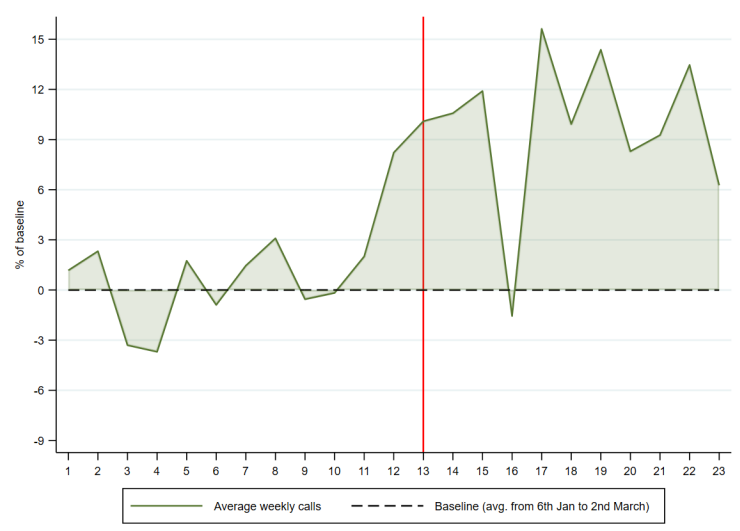

(b) second quartile of demand

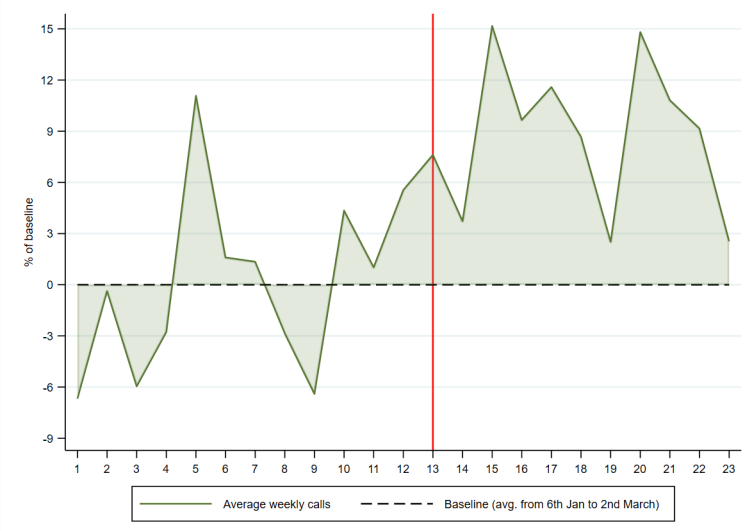

(d) highest quartile of demand

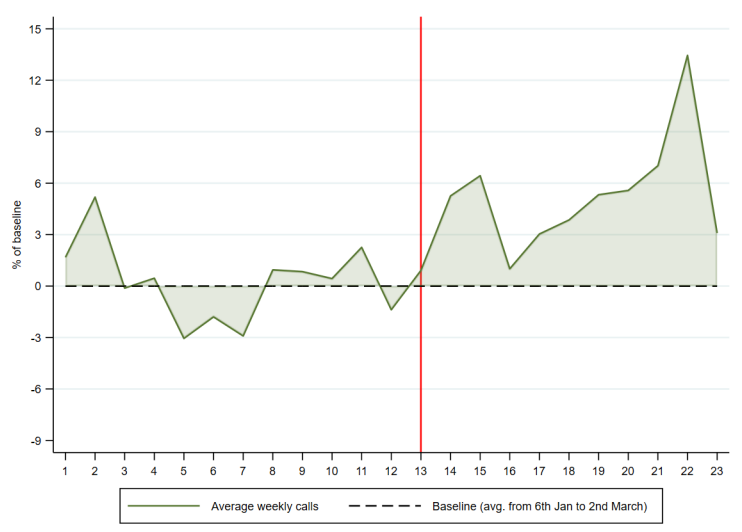

Note: The figure uses demand for policing in 2019 to divide output areas into 4 quartiles. Using these quartiles, the average weekly demand as a percentage of baseline in each quartile was computed for 2020 domestic abuse related calls-for-service. The baseline period used is 6th January 2020 to 2nd March 2020.The red line indicates the start of lockdown on 23rd March 2020. 
Figure A.7: Calls for service for domestic incidents/crimes, 2019 vs. 2020 by deprivation level

(a) least deprived areas

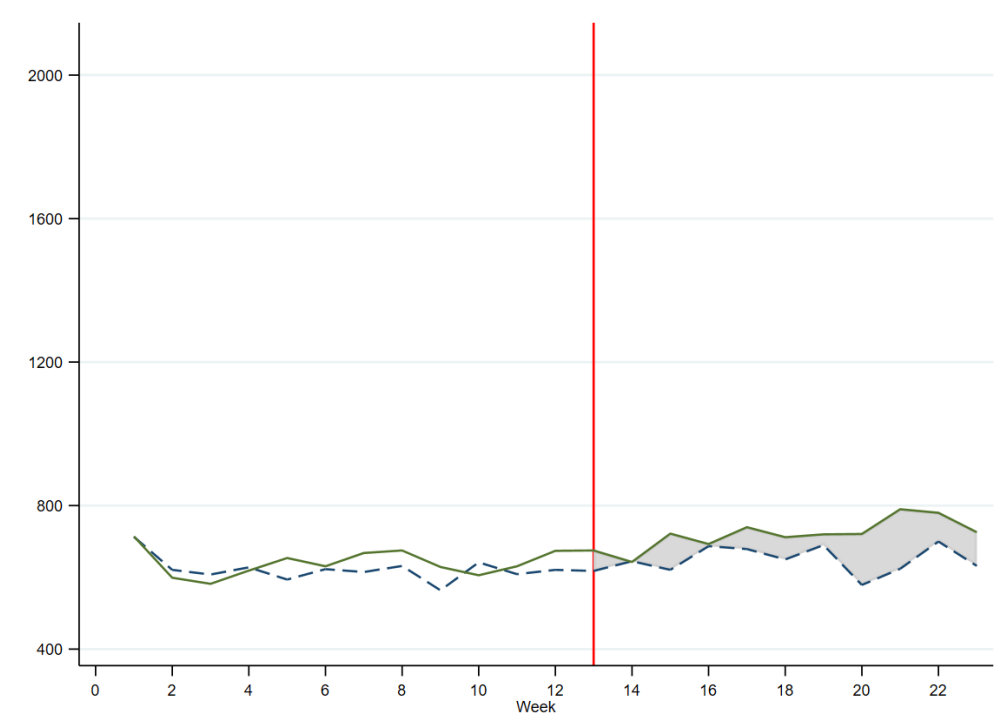

(b) most deprived areas

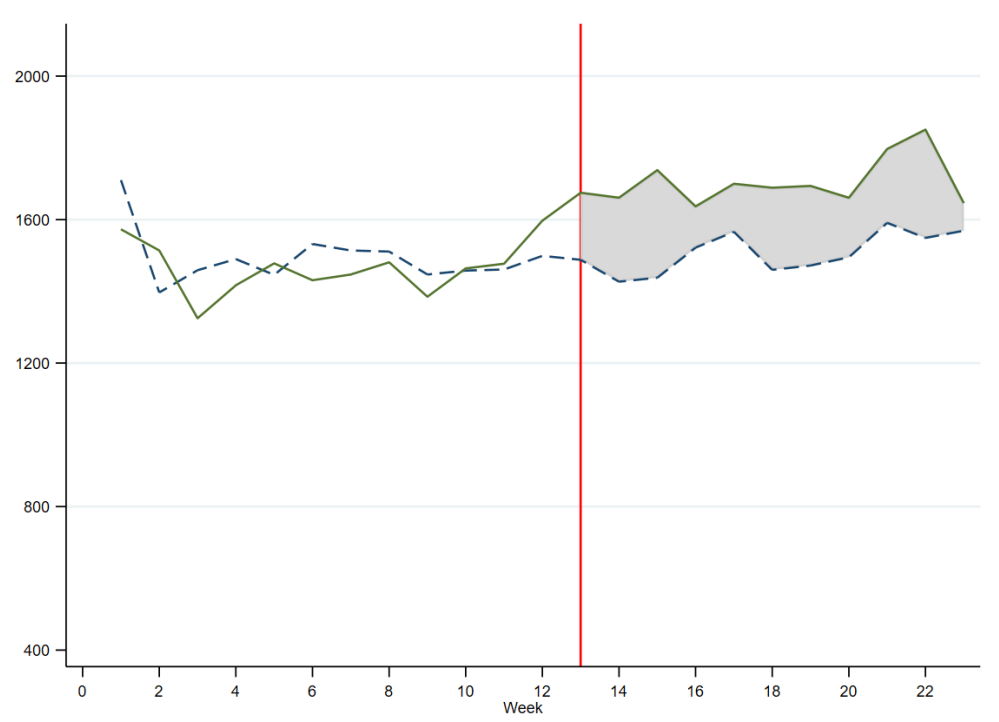

Note: The dotted line represents weekly calls for domestic incidents or crimes in 2019 and the solid line represents weekly calls in 2020. The shaded region represents the difference between the 2019 and 2020 weekly calls. The red line indicates the start of the lockdown on March 23rd, 2020. 
Figure A.8: Calls for service for domestic incidents/crimes as \% Baseline by deprivation level

(a) from areas with least deprived households

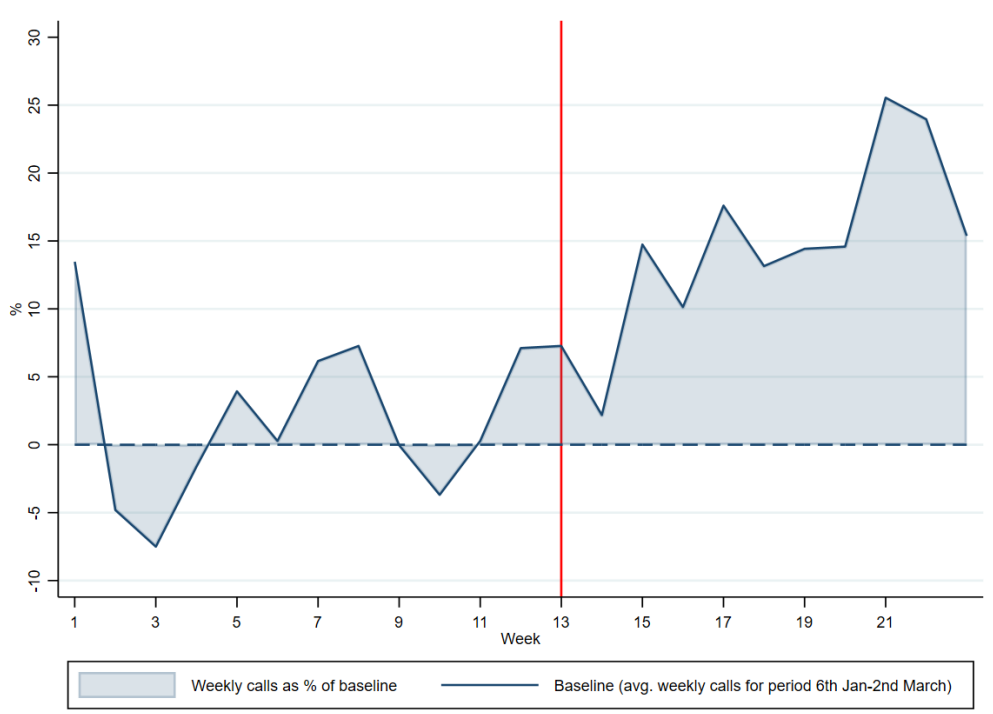

(b) from areas with most deprived households

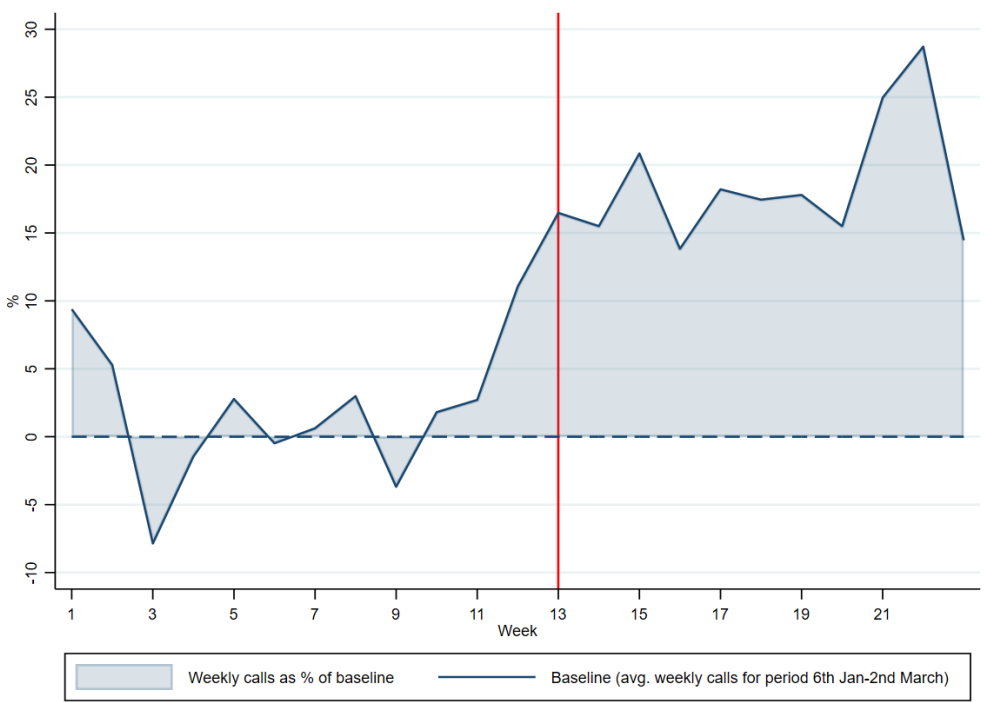

Note: The red line indicates the start of the lockdown on March 23rd, 2020. The dotted line indicates the baseline average associated with the deprivation category. The solid line shows the weekly calls as a percentage of baseline calls. The chosen baseline period is 6 January 2020 to 2 March 2020. 
Figure A.9: Calls for service for domestic incidents/crimes as in areas of moderate deprivation

(a) Calls for service for domestic incidents/crimes in areas of moderate deprivation, $2019 \mathrm{vs.}$ 2020

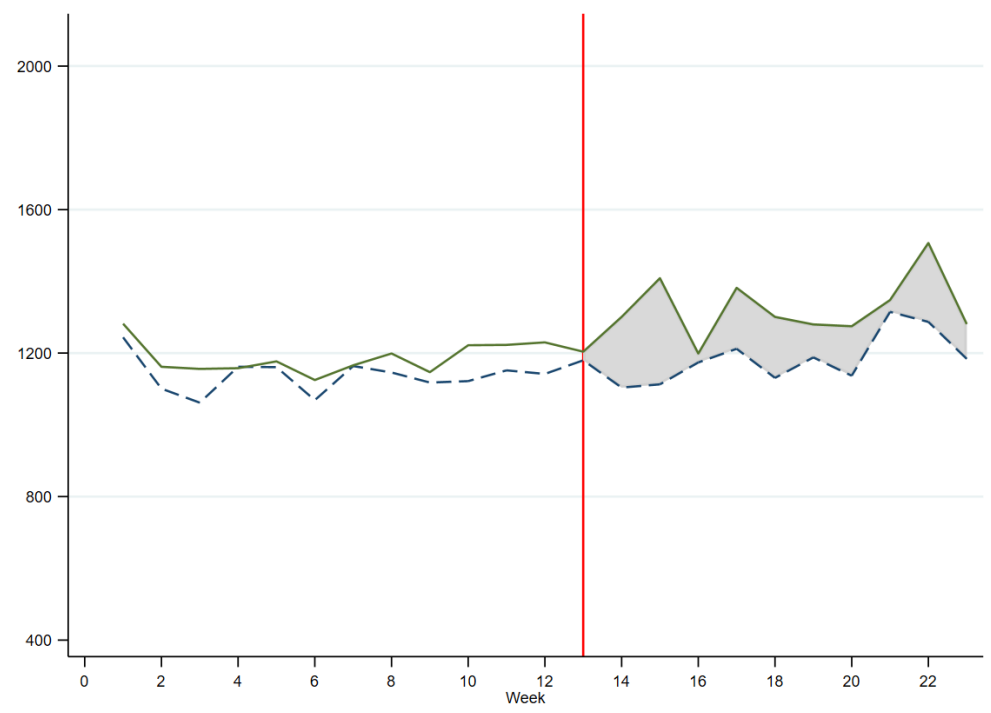

(b) Calls for service for domestic incidents/crimes as \% Baseline in areas of moderate deprivation

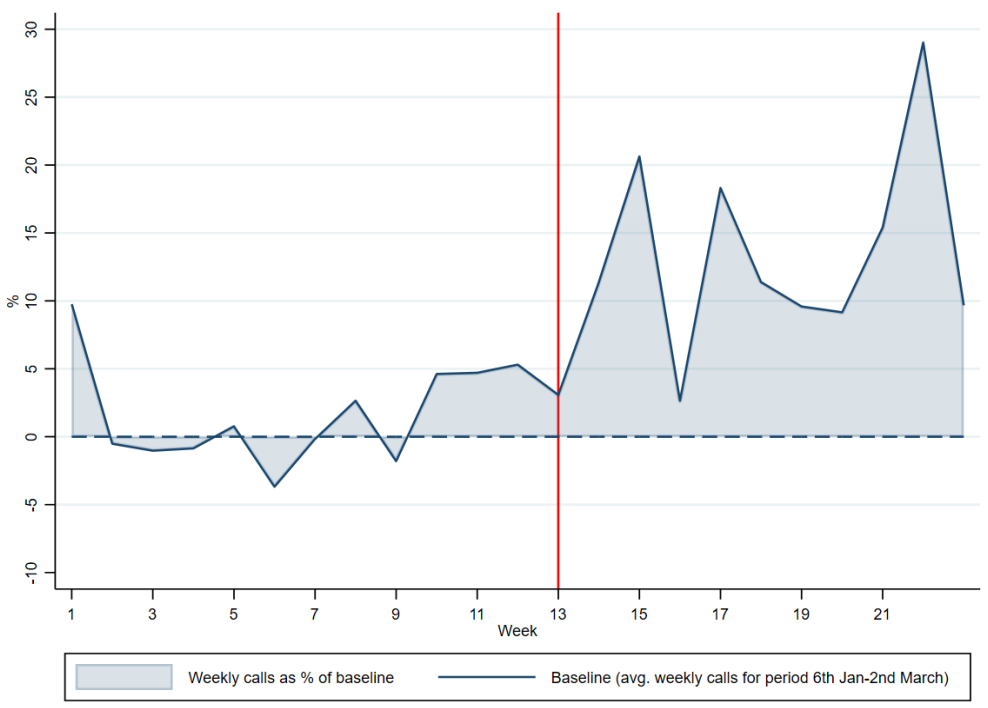

Note: In the first panel, the dotted line represents weekly calls for domestic incidents or crimes in 2019 and the solid line represents weekly calls in 2020. The shaded region represents the difference between the 2019 and 2020 weekly calls. The red line indicates the start of the lockdown on March 23rd, 2020. In the second panel, the dotted line indicates the baseline average associated with the deprivation category. The solid line shows the weekly calls as a percentage of baseline calls. The chosen baseline period is 6 January 2020 to 2 March 2020. 
Figure A.10: Calls for service for domestic incidents/crimes by caller type and deprivation level

(a) least deprived areas

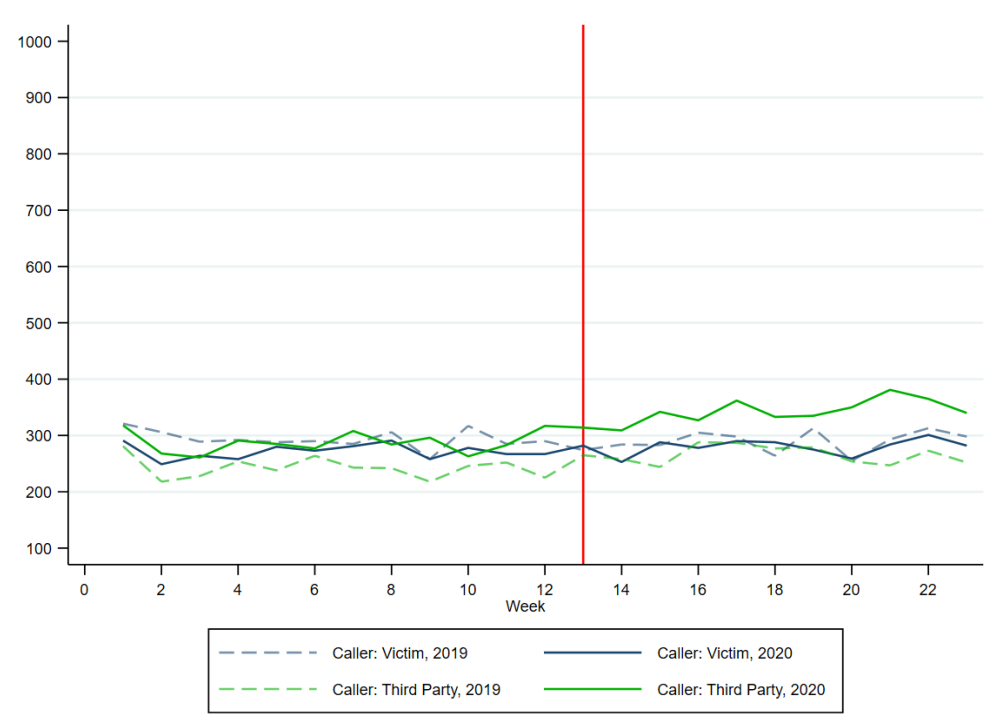

(b) most deprived areas

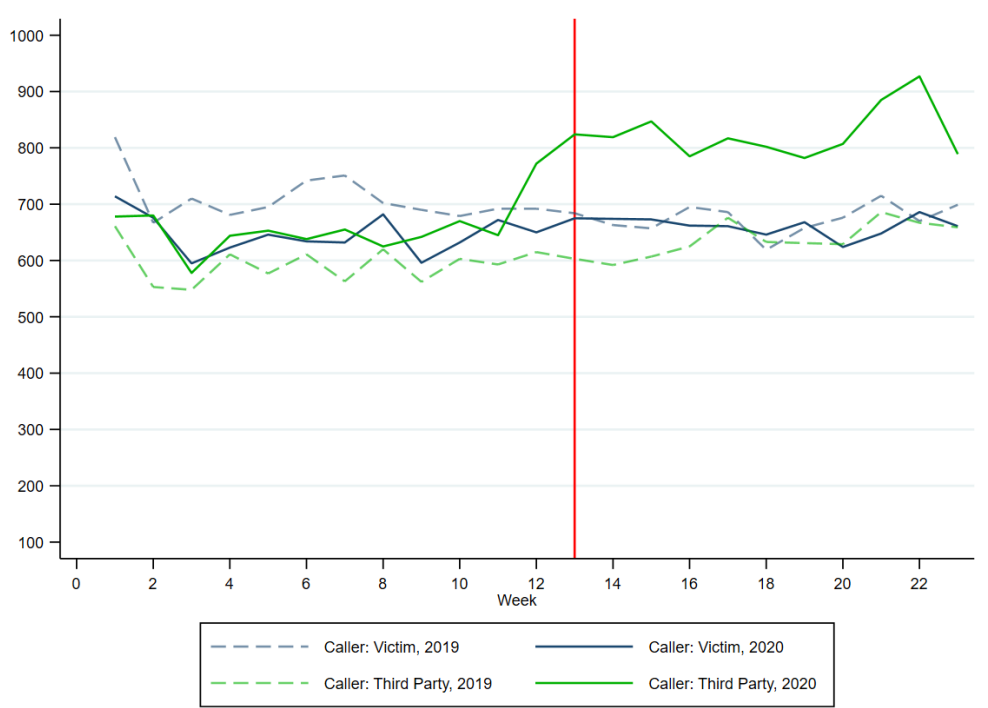

Note: The calls for service by caller type for the areas of average deprivation is reported in the Appendix. The red line indicates the start of the lockdown on 23rd March 2020. 
Figure A.11: Calls for service for domestic incidents/crimes by caller type for areas of moderate deprivation

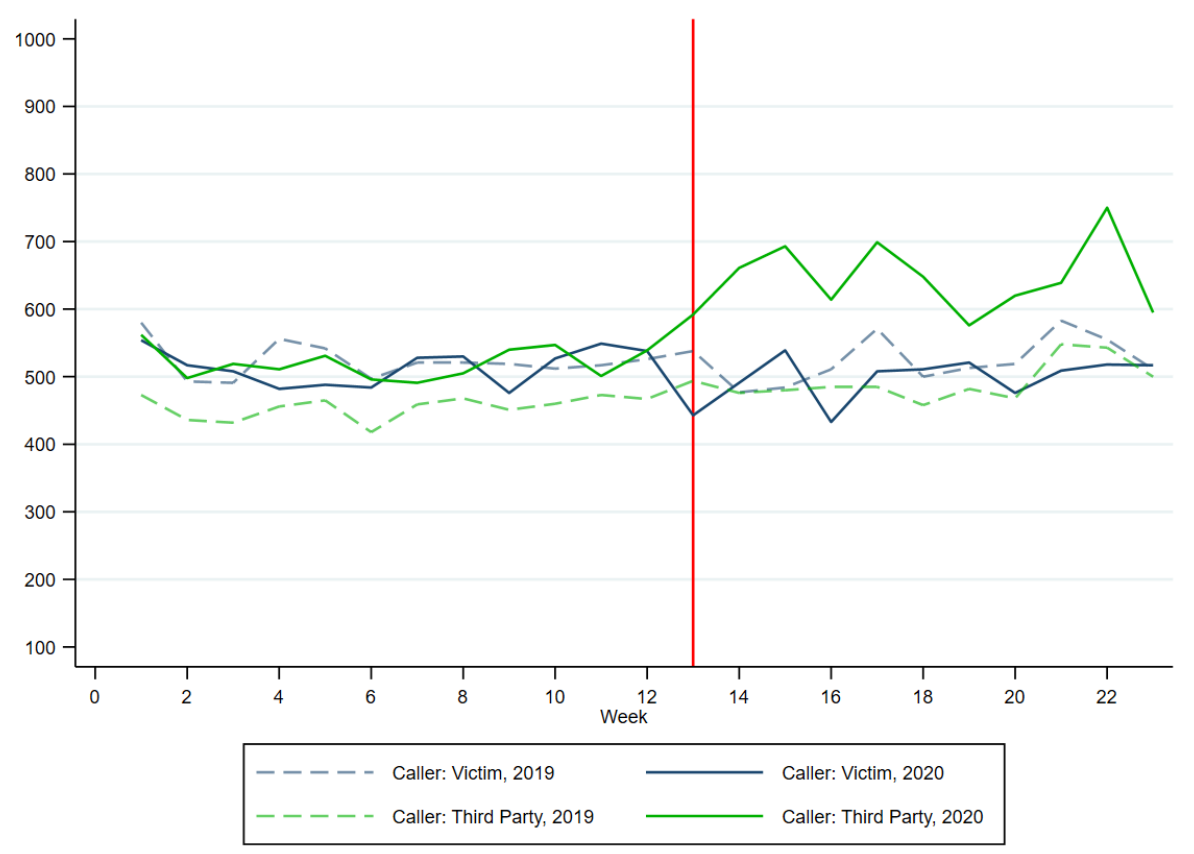

Note: The red line indicates the start of the lockdown on 23rd March, 2020. 
Figure A.12: Calls for service for domestic incidents/crimes, 2019 vs. 2020 by density level

(a) areas of low density

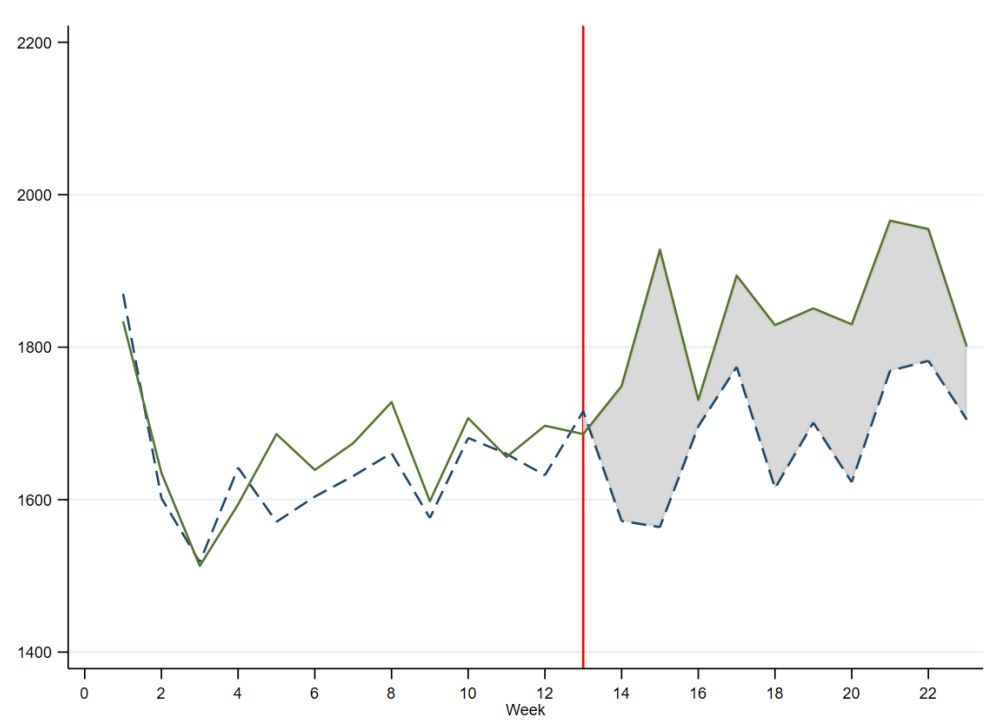

(b) areas of high density

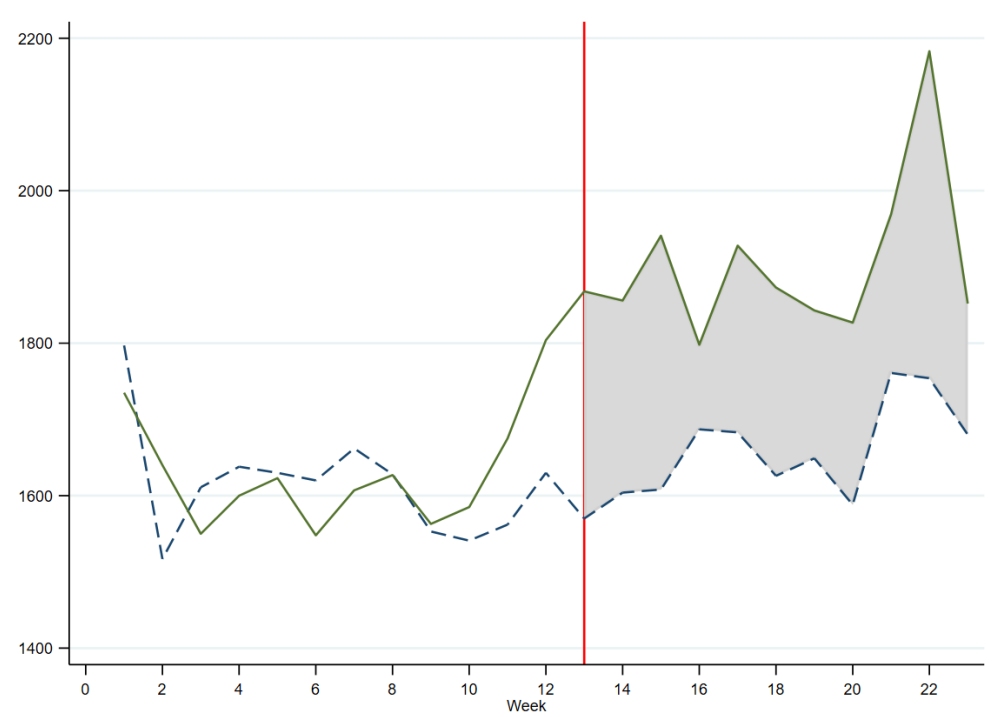

Note: The dotted line represents weekly calls for domestic incidents or crimes in 2019 and the solid line represents weekly calls in 2020. The shaded region represents the difference between the 2019 and 2020 weekly calls. The red line indicates the start of the lockdown on March 23rd, 2020. 
Figure A.13: Calls for service for domestic incidents/crimes, 2019 vs. 2020 in most deprived areas by density level

(a) most deprived areas with low density

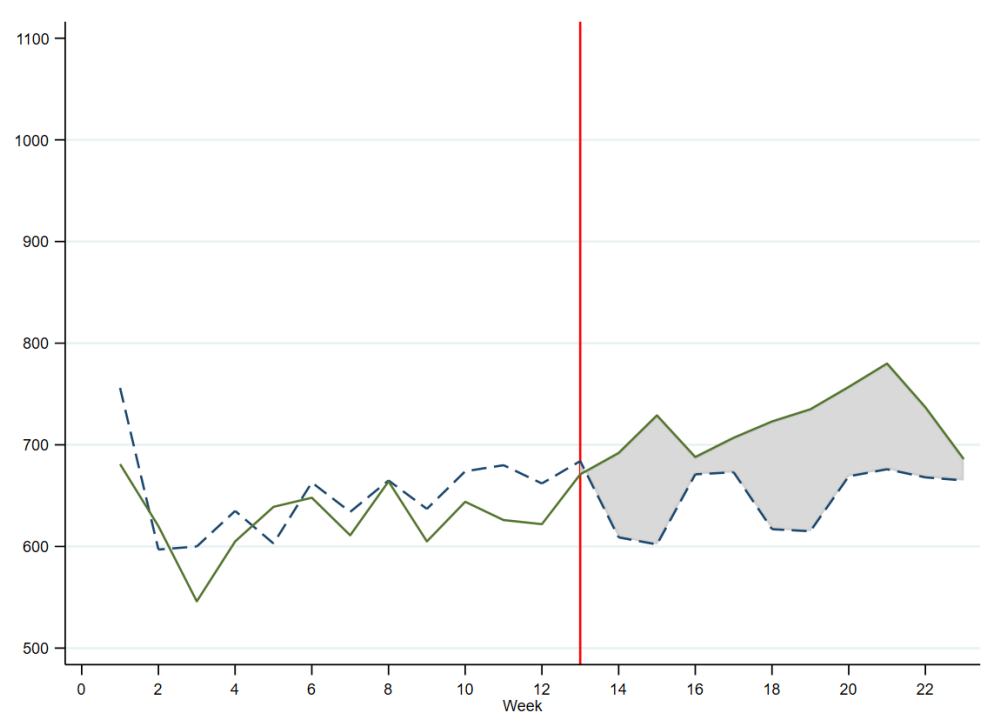

(b) most deprived areas with high density

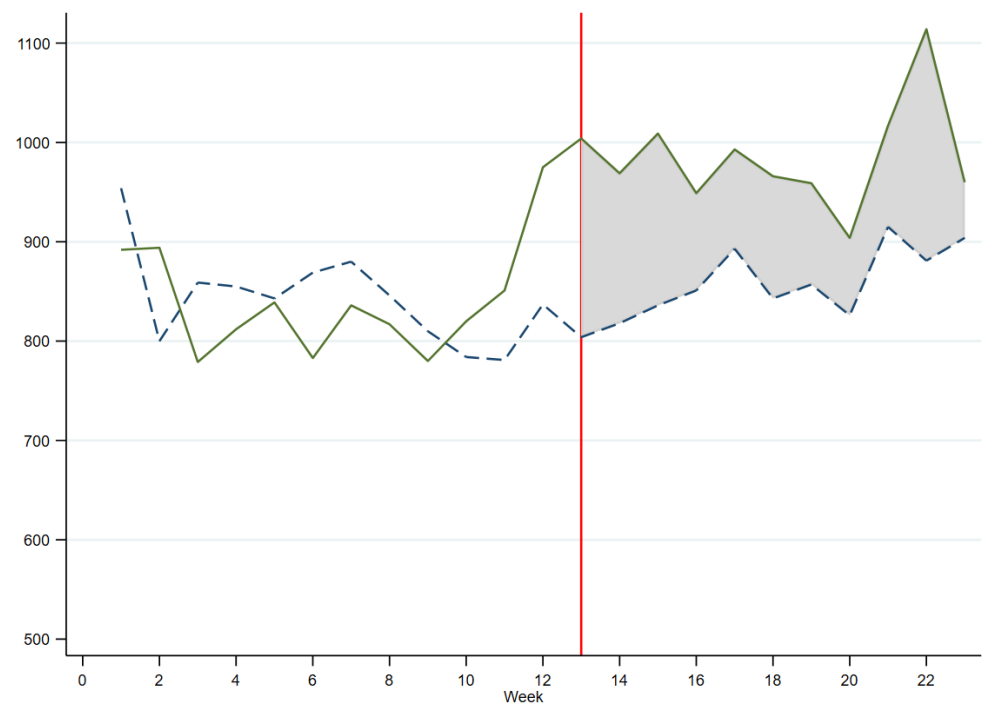

Note: The dotted line represents weekly calls for domestic incidents or crimes in 2019 and the solid line represents weekly calls in 2020. The shaded region represents the difference between the 2019 and 2020 weekly calls. The red line indicates the start of the lockdown on March 23rd, 2020. 
Figure A.14: Average daily calls for service for domestic incidents/crimes by deprivation level, 2019 vs. 2020

(a) least deprived areas

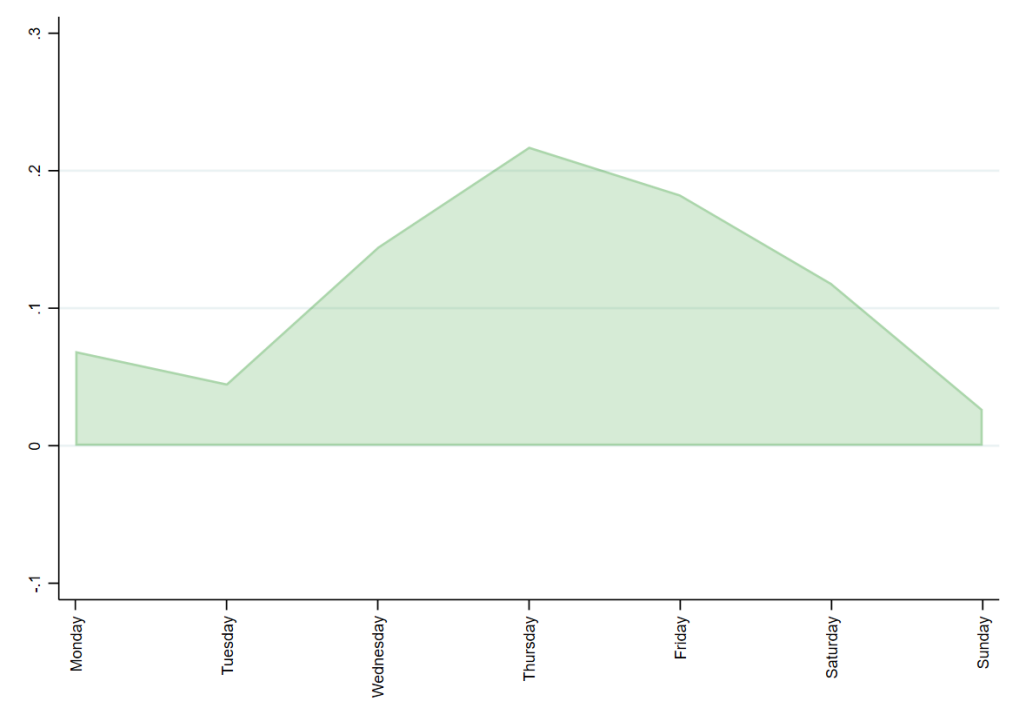

(b) most deprived areas

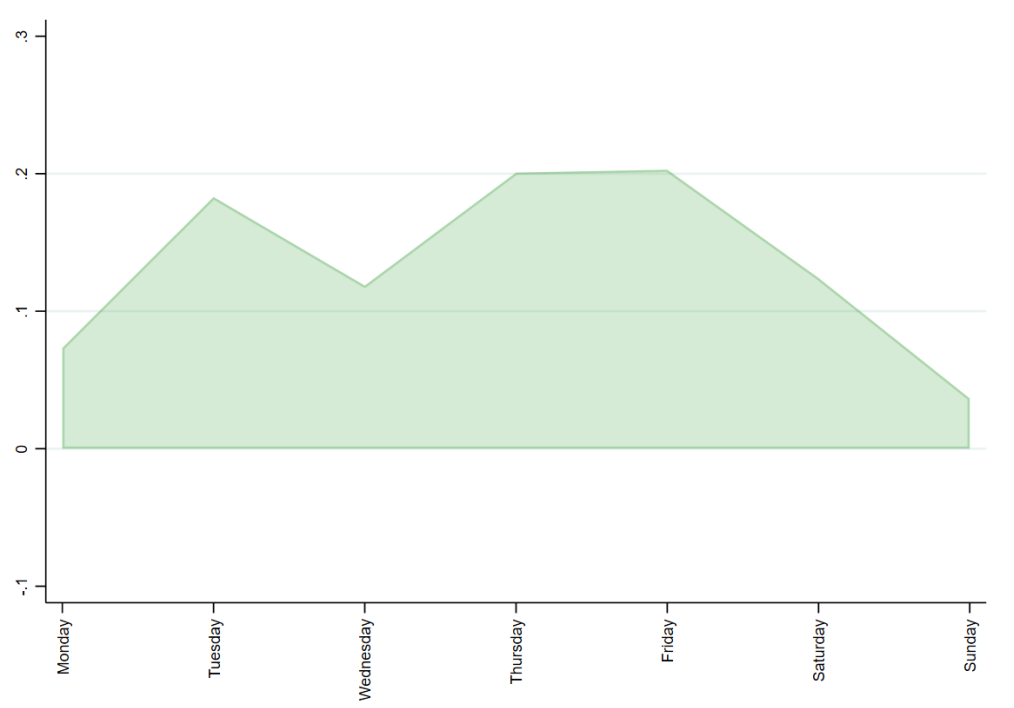

Note: The shaded area plots the difference average calls for service for domestic abuse incidents or crimes for the day of the week in 2019 and 2020 divided by average daily calls associated with that day of the week in 2019. For example, the shaded region in the panel for minimally deprived areas shows that average calls on Thursday during the lockdown in 2020 were $20 \%$ higher than the average calls on a Thursday in the same period in 2019. Average calls for both years have been computed only for the weeks after the lockdown was imposed. 
CENTRE FOR ECONOMIC PERFORMANCE

Recent Discussion Papers

\begin{tabular}{|c|c|c|}
\hline 1728 & $\begin{array}{l}\text { Jonathan Colmer } \\
\text { Ralf Martin } \\
\text { Mirabelle Muûls } \\
\text { Ulrich J. Wagner }\end{array}$ & $\begin{array}{l}\text { Does pricing carbon mitigate climate change? } \\
\text { Firm-level evidence from the European Union } \\
\text { emissions trading scheme }\end{array}$ \\
\hline 1727 & $\begin{array}{l}\text { Tony Beatton } \\
\text { Michael P. Kidd } \\
\text { Matteo Sandi }\end{array}$ & School indiscipline and crime \\
\hline 1726 & $\begin{array}{l}\text { Maximilian v. Ehrlich } \\
\text { Henry G. Overman }\end{array}$ & $\begin{array}{l}\text { Place-based policies and spatial disparities } \\
\text { across European cities }\end{array}$ \\
\hline 1725 & $\begin{array}{l}\text { Gabriel M. Ahlfeldt } \\
\text { Thilo N. H. Albers } \\
\text { Kristian Behrens }\end{array}$ & Prime Locations \\
\hline 1724 & $\begin{array}{l}\text { Benjamin Handel } \\
\text { Jonathan Kolstad } \\
\text { Thomas Minten } \\
\text { Johannes Spinnewijn }\end{array}$ & $\begin{array}{l}\text { The Social Determinants of Choice Quality: } \\
\text { Evidence from Health Insurance in the } \\
\text { Netherlands }\end{array}$ \\
\hline 1723 & $\begin{array}{l}\text { Claudia Hupkau } \\
\text { Barbara Petrongolo }\end{array}$ & $\begin{array}{l}\text { Work, Care and Gender During the Covid-19 } \\
\text { Crisis }\end{array}$ \\
\hline 1722 & $\begin{array}{l}\text { Ross Levine } \\
\text { Yona Rubinstein }\end{array}$ & $\begin{array}{l}\text { Selection Into Entrepreneurship and Self- } \\
\text { Employment }\end{array}$ \\
\hline 1721 & Sandra McNally & $\begin{array}{l}\text { Gender Differences in Tertiary Education: } \\
\text { What Explains STEM Participation? }\end{array}$ \\
\hline 1720 & $\begin{array}{l}\text { Edoardo di Porto } \\
\text { Paolo Naticchioni } \\
\text { Vincenzo Scrutinio }\end{array}$ & $\begin{array}{l}\text { Partial Lockdown and the Spread of Covid- } \\
\text { 19: Lessons From the Italian Case }\end{array}$ \\
\hline 1719 & $\begin{array}{l}\text { Swati Dhingra } \\
\text { Stephen Machin }\end{array}$ & The Crisis and Job Guarantees in Urban India \\
\hline
\end{tabular}




\begin{tabular}{|c|c|c|}
\hline 1718 & Stephen J. Redding & Trade and Geography \\
\hline 1717 & $\begin{array}{l}\text { Arun Advani } \\
\text { Felix Koenig } \\
\text { Lorenzo Pessina } \\
\text { Andy Summers }\end{array}$ & $\begin{array}{l}\text { Importing Inequality: Immigration and the } \\
\text { Top } 1 \text { Percent }\end{array}$ \\
\hline 1716 & $\begin{array}{l}\text { Pol Antràs } \\
\text { Stephen J. Redding } \\
\text { Esteban Rossi-Hansberg }\end{array}$ & Globalization and Pandemics \\
\hline 1715 & $\begin{array}{l}\text { Davin Chor } \\
\text { Kalina Manova } \\
\text { Zhihong Yu }\end{array}$ & $\begin{array}{l}\text { Growing Like China: Firm Performance and } \\
\text { Global Production Line Position }\end{array}$ \\
\hline 1714 & $\begin{array}{l}\text { Luna Bellani } \\
\text { Anselm Hager } \\
\text { Stephan E. Maurer }\end{array}$ & $\begin{array}{l}\text { The Long Shadow of Slavery: The Persistence } \\
\text { of Slave Owners in Southern Law-Making }\end{array}$ \\
\hline 1713 & $\begin{array}{l}\text { Mathias Huebener } \\
\text { Nico A. Siegel } \\
\text { C. Katharina Spiess } \\
\text { Gert G. Wagner } \\
\text { Sevrin Waights }\end{array}$ & $\begin{array}{l}\text { Parental Well-Being in Times of Covid-19 in } \\
\text { Germany }\end{array}$ \\
\hline 1712 & $\begin{array}{l}\text { Alan Manning } \\
\text { Graham Mazeine }\end{array}$ & $\begin{array}{l}\text { Subjective Job Insecurity and the Rise of the } \\
\text { Precariat: Evidence from the UK, Germany } \\
\text { and the United States }\end{array}$ \\
\hline 1711 & $\begin{array}{l}\text { Felipe Carozzi } \\
\text { Sandro Provenzano } \\
\text { Sefi Roth }\end{array}$ & Urban Censity and Covid-19 \\
\hline 1710 & $\begin{array}{l}\text { Jonas Jessen } \\
\text { C. Katharina Spiess } \\
\text { Sevrin Waights }\end{array}$ & Center-Based Care and Parenting Activities \\
\hline
\end{tabular}

The Centre for Economic Performance Publications Unit

Tel: +44 (0)207955 7673 Email info@cep.lse.ac.uk

Website: http://cep.lse.ac.uk Twitter: @CEP_LSE 